\title{
27

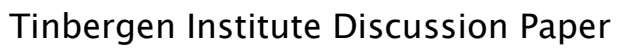 \\ Horizontal Multinational Firms, Vertical Multinational Firms and Domestic Investment
}

Julian Emami Namini

Enrico Pennings*

Erasmus School of Economics, Erasmus University Rotterdam.

* Tinbergen Institute. 


\section{Tinbergen Institute}

The Tinbergen Institute is the institute for economic research of the Erasmus Universiteit Rotterdam, Universiteit van Amsterdam, and Vrije Universiteit Amsterdam.

Tinbergen Institute Amsterdam

Roetersstraat 31

1018 WB Amsterdam

The Netherlands

Tel.: +31(0)205513500

Fax: $+31(0) 205513555$

Tinbergen Institute Rotterdam

Burg. Oudlaan 50

3062 PA Rotterdam

The Netherlands

Tel.: + $31(0) 104088900$

Fax: $+31(0) 104089031$

Most TI discussion papers can be downloaded at http://www.tinbergen.nl. 


\title{
Horizontal multinational firms, vertical multinational firms and domestic investment*
}

\author{
Julian Emami Namini ${ }^{\dagger}$ and Enrico Pennings ${ }^{\ddagger}$
}

January 14, 2009

\begin{abstract}
We build a dynamic general equilibrium model with 2 countries, horizontal and vertical multinational activity and endogenous domestic and foreign investment. It is found that horizontal multinational activity always leads to a complementary relationship between domestic and foreign investment. Vertical multinational activity, in contrast, leads to either a substitutional or complementary relationship between domestic and foreign investment, depending on the firms' technologies. We test the theoretical implications with a panel of U.S. multinationals and find empirical support.
\end{abstract}

JEL classification: E22, F21, F23

Keywords: Horizontal multinational firms, vertical multinational firms, domestic investments, neoclassical growth model

${ }^{*}$ We would like to thank Carlo Altomonte and seminar participants at the ETSG 2008 Meeting, Midwest International Economics Fall 2008 Meeting and the University of Strathclyde for helpful comments. All errors are our responsibility.

${ }^{\dagger}$ Corresponding author: Department of Economics, Erasmus University Rotterdam, PO Box 1738, 3000DR Rotterdam, the Netherlands, emami@few.eur.nl.

${ }^{\ddagger}$ Department of Applied Economics, Erasmus University Rotterdam, PO Box 1738, 3000DR Rotterdam, the Netherlands, pennings@few.eur.nl. 


\section{Introduction}

Rising multinational activity in the recent past has raised important questions about how multinational activity affects domestic capital formation. While Feldstein (1995) finds a negative correlation between foreign direct investment (FDI) and domestic investment for OECD countries, Desai et al. (2005a) find a positive correlation for the U.S. These conflicting results indicate that neither an optimistic nor a pessimistic view on the domestic consequences of FDI might capture the full story.

Intuitively, a distinction between the motives for FDI is crucial for understanding the relation between domestic and foreign capital expenditures. While horizontal multinationals invest abroad in order to serve new markets, vertical multinationals invest abroad in order to reduce their production costs. Therefore, the aggregate finding of foreign and domestic capital expenditures being substitutes or complements may be rather distinct for either of the two types of multinationals.

Our paper intends to contribute to the debate by building a general equilibrium model, which extends Markusen's (2002) Knowledge-Capital model of the multinational firm by endogenous domestic and foreign capital expenditures. Since the Knowledge-Capital model explains the emergence of both horizontal and vertical multinational firms, we can analyze the relation between domestic and foreign capital expenditures under different motives for FDI. Afterwards, we test the theoretical implications with U.S. data on the operations of multinational firms. Our theoretical and empirical results show that the link between domestic and foreign capital expenditures crucially differs between horizontal and vertical FDI.

Our paper is therefore in line with other recent research on the domestic consequences of FDI. Braunerhjelm et al. (2005) and Arndt et al. (2007) also consider that the motives for FDI matter for the relationship between domestic and foreign capital expenditures. In contrast to them, we derive our hypotheses from a general equilibrium model with endogenous capital expenditures and we bring our hypotheses directly to the data.

The empirical literature on the link between domestic and foreign investment has started with Feldstein (1995) who found a negative correlation between FDI and domestic investment in a sample of OECD countries, suggesting that outward FDI reduces domestic investment. More recently, Desai et al. (2005a) redid his analysis on a subsample of domestic investment and FDI by examining domestic and foreign capital expenditures of U.S. multinationals. Instead of a negative relation between domestic and foreign capital expenditures, they find a positive and significant link between the two variables. One possible explanation they put forward is that the USA may be different from other OECD countries. Herzer and Schrooten (2008) provide some evidence for this explanation since they find substitutability 
between domestic and foreign investment for German data while they find complementary for U.S. data. A second explanation Desai et al. (2005a) put forward relates to the activities of multinational firms which are different from the activities of the average firm. A third explanation relates to the composition of FDI and domestic investment in both samples in the sense that aggregate FDI data contain financing flows whereas the data for multinationals are restricted to capital expenditures. In a pooled panel of U.S. multinationals with more than 2,000 observations and period fixed effects, Desai et al. (2005b) find that a 10\% increase in foreign investment increases domestic investments by approximately $2 \%$, confirming the aggregate results.

Our theoretical results show that horizontal multinational activity leads to a complementary relationship between domestic and foreign FDI, irrespective of the firms' technologies. Vertical multinational activity, in contrast, leads to a substitutional relationship between domestic and foreign investment if $(i)$ the factor shares of the firm's domestic and foreign intermediate goods differ sufficiently or if $(i i)$ domestic and foreign intermediate goods have sufficiently different shares in the firm's final good.

We test the implications of our theoretical model in an econometric analysis using a U.S. panel of foreign and domestic investments at the sector level over the period 1999-2005. In order to test the implications from the theoretical model, we test whether the link between domestic and foreign investment is different for horizontal and vertical multinationals.

If we do not distinguish between horizontal and vertical FDI, the results of our panel with random and fixed sector effects confirm the findings by Desai et al. (2005b) for the sign of foreign investment. In order to distinguish between horizontal and vertical multinationals, we follow empirical evidence by Hanson et al. (2001) and assume that firms in the manufacturing sectors are mainly vertical multinationals while multinationals operating in the other sectors are mainly horizontal. ${ }^{1}$ We find a complementary relation between domestic and foreign investment for horizontal multinationals, but find a substitutional relation for vertical multinationals. If we further refine the link between domestic and foreign investments, the econometric results show that the substitution effect for vertical MNE is moderated if the factor shares of the intermediate goods are more equal and if the shares of the intermediate goods in final goods production are more equal. This result is also predicted by the theoretical model.

This paper is organized as follows. Section 2 describes the theoretical model. Section 3 performs a comparative steady state analysis of the theoretical model and derives empirically

\footnotetext{
${ }^{1}$ We also provide empirical evidence, suggesting that this way to distinguish between horizontal and vertical FDI is appropriate.
} 
testable predictions. Section 4 tests the theoretical predictions. Section 5 concludes.

\section{Basic model}

\section{$2.1 \quad$ Overview}

This paper analyzes a general equilibrium model, which is a dynamic extension of the Knowledge-Capital model by Markusen (2002). The model consists of two countries, a home country $H$ and a foreign country $F$.

The representative household in each country consumes several varieties of a differentiated good $X$ and a homogeneous good $Z$. Good $X$ is produced by multinational firms.

It is assumed that households aggregate the varieties of good $X$ according to a CESfunction like in Dixit and Stiglitz (1977). Furthermore, it is assumed that the number of firms in sector $X$ is sufficiently large so that the market for good $X$ is characterized by largegroup monopolistic competition (e.g., Markusen and Venables, 2000). Sector $Z$ firms behave perfectly competitively.

The home country $H$ and the foreign country $F$ are endowed with two factors of production, labor $L$ and capital $K$, which are mobile between sectors but immobile between countries. Labor and capital are used for the following production activities: first, both factors are used to produce the homogeneous final good $Z$. Second, labor and capital are used to produce two intermediate goods $v_{1}$ and $v_{2}$; both intermediate goods are assembled to give a unique variety of the differentiated final good $X$.

Each country's labor endowment is constant over time. Each country's capital endowment, in contrast, is determined endogenously via the Ramsey growth model and therefore flexible in the long-run. Relative factor endowments are therefore flexible in the long-run as well. Due to this dynamic extension of Markusen's (2002) Knowledge-Capital model the firm regime has to be determined exogenously. In the first regime, only horizontal multinational firms are active. In the second regime, only vertical multinational firms are active.

The reason for the exogenous determination of the firm regime is the following: in the dynamic setup of this paper, a unique causal relationship between the firm regime and the countries' relative factor endowments is missing. On the one hand, the firm regime influences relative factor demands by firms and, therefore, the countries' relative factor endowments in the steady state. ${ }^{2}$ On the other hand, the countries' relative factor endowments influence relative factor prices and, therefore, the firm regime. ${ }^{3}$

\footnotetext{
${ }^{2}$ Baxter (1992) shows that a country's relative factor endowments in the steady state of a Ramsey growth model depend on the firms' factor demands.

${ }^{3}$ The Knowledge-Capital model by Markusen (2002) explains the influence of the countries' relative factor endowments on the firm regime. Note that the Knowledge-Capital model is a static model, i.e. the relative
} 
Two different general steady state equilibria accordingly exist in this dynamic setup. First, a general equilibrium with horizontal multinational firms and the corresponding relative factor endowments in the steady state. Second, a general equilibrium with vertical multinational firms and the corresponding relative factor endowments in the steady state. This paper accordingly determines the firm regime exogenously. Afterwards, the countries' corresponding (relative) factor endowments in the steady state are derived.

In the first firm regime with only horizontal multinational firms, each firm has two production plants, one in country $H$ and one in country $F$. Both production plants produce both intermediate goods $v_{1}$ and $v_{2}$. In the second firm regime with only vertical multinational firms, each firm has also two production plants, one in country $H$ and one in country $F$. However, each production plant produces only one of the two intermediate goods $v_{1}$ and $v_{2} \cdot{ }^{4}$ Both horizontal and vertical multinational firms produce with economies of scale, which are due to the existence of fixed production costs.

Several assumptions are necessary in order to get straightforward analytical results. First, both countries are completely identical with respect to technology parameters and preference parameters; only the income share households spend on the varieties of good $X$ and on good $Z$ is allowed to differ between countries. Second, international trade of both intermediate goods, the varieties of good $X$ and good $Z$ is assumed to be costless. Third, this paper assumes that either only horizontal multinational firms or only vertical multinational firms are active. Fourth, this paper assumes a specific ranking of the factor intensities of all 4 goods; still, this ranking is in line with previous empirical studies. Finally, the model only considers the countries' steady states; therefore, the time index is included only when necessary.

In order to analyze whether domestic and foreign capital expenditures are complements or substitutes, the steady state of the 2-country world will be disturbed by four persistent exogenous shocks: a symmetric and an asymmetric increase in country size and a symmetric and an asymmetric demand shift towards the multinational firms' good.

If the capital stocks of both countries move into the same direction due to the exogenous shock, domestic and foreign capital expenditures are complements. If the capital stocks of both countries move into different directions due to the exogenous shock, domestic and foreign

\footnotetext{
factor endowments are exogenously given and are not influenced by the firm regime.

${ }^{4}$ Note that the definition of vertical multinational firms in this paper differs from the definition of vertical multinational firms in the Knowledge-Capital model by Markusen (2002). There are no intermediate goods in the Knowledge-Capital model. In the Knowledge-Capital model vertical multinational firms produce the final good directly with labor and capital in one country only; headquarter services are produced in the other country and are exported to the production plant. The additional separation of the production process into two intermediate goods like in this paper takes into account that vertical multinational firms in general never separate the entire production process from the headquarter services, but only the most labor intensive part of the production process (e.g., UNCTAD, 2007).
} 
capital expenditures are substitutes.

The following subsections separately describe the ingredients into the dynamic general equilibrium model. Subsection 2.2 describes the production side of both countries, subsection 2.3 describes the dynamic structure of the model, subsection 2.4 derives factor price equalization between both countries in the steady state, subsection 2.5 defines horizontal and vertical multinational firms and subsection 2.6 describes the demand side of both countries. Subsections 2.7 and 2.8 describe two additional conditions which have to hold in each period of the steady state: first, the free entry condition in the multinational firms' sector and, second, the trade balance equation.

\subsection{Production}

Both countries have the same technologies for producing all goods.

The homogeneous good $Z$ is produced according to the following Cobb-Douglas production function:

$$
Z=\frac{L^{\beta} \cdot K^{1-\beta}}{\beta^{\beta} \cdot(1-\beta)^{1-\beta}}
$$

since good $Z$ represents the average outside good, its factor shares are assumed to be 'average' as well. Therefore, $\beta$ will be set equal to 0.5 during the comparative steady state analysis in section 3. The per unit cost function which is dual to the production function in equation (1) is given by:

$$
c_{Z}\left(w_{i}, r_{i}\right)=w_{i}^{\beta} \cdot r_{i}^{1-\beta}
$$

where $w_{i}$ and $r_{i}$ stand for the price per unit labor and the capital rental rate in country $i$. Since sector $Z$ firms behave perfectly competitively, they sell their good at price $p_{Z}=c_{Z}$.

Intermediate goods $v_{1}$ and $v_{2}$ are produced according to the following Cobb-Douglas production functions:

$$
\begin{aligned}
& v_{1}=\frac{L^{\phi_{1}} \cdot K^{1-\phi_{1}}}{\phi_{1}^{\phi_{1}} \cdot\left(1-\phi_{1}\right)^{1-\phi_{1}}}, \quad \text { with } 0 \leq \phi_{1}<0.5, \\
& v_{2}=\frac{L^{\phi_{2}} \cdot K^{1-\phi_{2}}}{\phi_{2}^{\phi_{2}} \cdot\left(1-\phi_{2}\right)^{1-\phi_{2}}}, \quad \text { with } \phi_{2}=1-\phi_{1} .
\end{aligned}
$$

Note that intermediate good $v_{1}$ is assumed to be more capital intensive than the outside good $Z$, while intermediate good $v_{2}$ is assumed to be more labor intensive than the outside good $Z$. These assumptions on $\phi_{1}$ and $\phi_{2}$ therefore allow to consider the empirical regularity that multinational firms, if they are vertical, relocate the most labor intensive production activities to the relatively labor rich country, while they keep the more capital intensive production activities in the relatively capital rich country (Blomström and Kokko, 1997; Hummels et 
al., 1998; UNCTAD, 2007). ${ }^{5}$ The marginal cost functions which are dual to the production functions in equations (3) and (4) are given by:

$$
c_{v_{1}}\left(w_{i}, r_{i}\right)=w_{i}^{\phi_{1}} \cdot r_{i}^{1-\phi_{1}} \quad \text { and } \quad c_{v_{2}}\left(w_{i}, r_{i}\right)=w_{i}^{\phi_{2}} \cdot r_{i}^{1-\phi_{2}}, \quad i=H, F .
$$

Intermediate goods $v_{1}$ and $v_{2}$ are assembled to a unique variety of the differentiated final good $X$ according to the following Cobb-Douglas production function:

$$
X=\frac{v_{1}^{\alpha} \cdot v_{2}^{1-\alpha}}{\alpha^{\alpha} \cdot(1-\alpha)^{1-\alpha}}, \text { with } 0.5<\alpha \leq 1 .
$$

The parameter restrictions $0 \leq \phi_{1}<0.5$ and $0.5<\alpha \leq 1$ imply that good $X$ is produced capital intensively relative to $\operatorname{good} Z$.

The per unit cost function which is dual to the production function in equation (6) is given by:

$c_{X}\left(w_{i}, w_{j}, r_{i}, r_{j}\right)=c_{v_{1}}^{\alpha} \cdot c_{v_{2}}^{1-\alpha}=w_{i}^{\phi_{1} \cdot \alpha} \cdot w_{j}^{\phi_{2} \cdot(1-\alpha)} \cdot r_{i}^{\alpha \cdot\left(1-\phi_{1}\right)} \cdot r_{j}^{\left(1-\phi_{2}\right) \cdot(1-\alpha)}, \quad i, j=H, F$.

\subsection{Dynamic structure}

The model is extended to a Ramsey growth setup. Including the time index $t$, utility in a single period $t$ in country $i, i=H, F$, is given by the following Cobb-Douglas function:

$$
U_{i, t}=X_{i, t}^{\gamma_{i}} \cdot Z_{i, t}^{1-\gamma_{i}}, \quad 0<\gamma_{i}<1,
$$

where $X_{i, t}$ denotes a CES-aggregate of all consumed varieties of good $X$ in period $t$ in country $i$ and $Z_{i, t}$ the consumption of good $Z$ in period $t$ in country $i$. The parameter $\gamma_{i}$ has the index $i$ since it is allowed to differ between countries.

Country $i$ 's capital stock $K_{i, t}$ in period $t$ is determined endogenously via the investment decision by country $i$ 's representative household. It is assumed that only good $Z$ is used for investment. The household chooses the consumption and investment level in each period such that lifetime utility $V$ is maximized. If $\rho$ denotes the time discount rate, lifetime utility of the households is given by: 6

$$
V_{i}=\sum_{t=0}^{\infty} \frac{1}{(1+\rho)^{t}} \cdot u\left(U_{i, t}\right)
$$

where $u$ represents the household's instantaneous utility function.

\footnotetext{
${ }^{5}$ The assumption that $\phi_{2}$ exactly equals $1-\phi_{1}$ simplifies calculations, but is not crucial for the final results.

${ }^{6}$ All parameters without a country index are assumed to be identical across countries.
} 
If $\delta$ stands for the depreciation rate for capital, investment into the country's capital stock in period $t$ of the steady state is given by: ${ }^{7}$

$$
I_{i, t}=K_{i, t+1}-(1-\delta) \cdot K_{i, t} .
$$

$I_{i, t}$ denotes the amount of good $Z$, which is invested in period $t$. Equation (10) implies that one unit of good $Z$, which is invested in period $t$, leads to one unit of capital in period $t+1$.

It is assumed that the country's household and sector $Z$-firms behave perfectly competitively. The household owns the production factors and lends them out to firms for production purposes. The steady state of the economy is then described by several necessary first order conditions. $^{8}$ Four of these necessary first order conditions already determine the country's factor price ratio in the steady state:

$$
\begin{aligned}
r_{i, t}+(1-\delta) \cdot p_{Z, i, t} & =p_{K, i, t} \\
r_{i, t} & =p_{Z, i, t} \cdot\left(\frac{1-\beta}{\beta} \cdot \frac{L_{Z, i, t}}{K_{Z, i, t}}\right)^{\beta} \\
w_{i, t} & =p_{Z, i, t} \cdot\left(\frac{\beta}{1-\beta} \cdot \frac{K_{Z, i, t}}{L_{Z, i, t}}\right)^{1-\beta} \\
\frac{p_{K, i, t+1}}{1+\rho} & =p_{Z, i, t},
\end{aligned}
$$

where $p_{K, i, t}$ denotes the price per unit capital in country $i$ period $t$ and $L_{Z, i, t}$ and $K_{Z, i, t}$ the labor and capital input in sector $Z$ of country $i$ in period $t$.

Equation (11) is the arbitrage condition for the household's capital lending behavior: households are only willing to lend out capital to firms if the capital rental rate $r_{i, t}$ plus the value of the remaining unit of capital in period $t+1$, which is given by $(1-\delta) \cdot p_{Z, i, t}$, equals the price per unit capital today.

Equations (12) and (13) are the usual conditions for a profit maximizing factor input choice by firms.

Equation (14) denotes the Euler equation, which describes the dynamically optimizing behavior of a household: the household chooses the investment level such that, in the steady state, the discounted value of a unit capital in $t+1$ equals the value of a unit of good $Z$ in $t$.

The time index $t$ is omitted from now on since only the steady state is considered in the following.

Substituting equation (14) into equation (11) leads to $r_{i}+(1-\delta) \cdot p_{Z, i}=(1+\rho) \cdot p_{Z, i}$, which can be simplified to $\frac{r_{i}}{p_{Z, i}}=\rho+\delta$.

\footnotetext{
${ }^{7}$ Note that the country's labor endowment is assumed to be constant over time. Investment in the steady state therefore only compensates for depreciation.

${ }^{8}$ Cf. Baxter (1992), p. 738, for these necessary first order conditions.
} 
Substituting $\frac{r_{i}}{p_{Z, i}}=\rho+\delta$ into equation (12) and solving for $\frac{K_{Z, i}}{L_{Z, i}}$ results in $\frac{K_{Z, i}}{L_{Z, i}}=\frac{1-\beta}{\beta}$. $\left(\frac{1}{\rho+\delta}\right)^{1 / \beta}$.

Substituting $\frac{K_{Z, i}}{L_{Z, i}}=\frac{1-\beta}{\beta} \cdot\left(\frac{1}{\rho+\delta}\right)^{1 / \beta}$ into equation (13) results in $\frac{w_{i}}{p_{Z, i}}=(\rho+\delta)^{(\beta-1) / \beta}$. Dividing $\frac{w_{i}}{p_{Z, i}}$ by $\frac{r_{i}}{p_{Z, i}}$ gives:

$$
\frac{w_{i}}{r_{i}}=(\rho+\delta)^{-1 / \beta}
$$

The further analysis simplifies considerably since, in this dynamic setup, the factor price ratio in the steady state is already determined by the parameters $\rho, \delta$ and $\beta$. Therefore, in this dynamic setup, it is not necessary to take the factor market equilibrium conditions to determine the factor price ratio in the steady state. ${ }^{9}$

Instead, the factor price ratio from equation (15) can be substituted into the factor market equilibrium conditions. The factor market equilibrium conditions can then be used to solve for the steady state capital stock, which is endogenous in this dynamic setup. Furthermore, section 3 shows that the factor market equilibrium conditions can be used to solve for the number of multinational firms in the steady state.

Most importantly, section 3 shows that the factor market equilibrium conditions are linear in the steady state capital stock and the number of firms, i.e. the factor market equilibrium conditions can be solved analytically for these two variables.

\subsection{Factor price equalization in the steady state}

The assumption of identical technologies and preferences in both countries implies that the parameters $\rho, \delta$ and $\beta$ are identical in both countries, i.e. $\frac{w_{H}}{r_{H}}$ equals $\frac{w_{F}}{r_{F}}$ due to equation (15). Furthermore, costless trade of good $Z$ between countries leads to:

$$
\begin{gathered}
p_{Z, H}=w_{H}^{\beta} \cdot r_{H}^{1-\beta}=w_{F}^{\beta} \cdot r_{F}^{1-\beta}=p_{Z, F} \\
\Longleftrightarrow\left(\frac{w_{H}}{r_{H}}\right)^{\beta} \cdot r_{H}=\left(\frac{w_{F}}{r_{F}}\right)^{\beta} \cdot r_{F} .
\end{gathered}
$$

Since $\frac{w_{H}}{r_{H}}=\frac{w_{F}}{r_{F}}$ in the steady state, equation (17) implies that $r_{H}=r_{F}$ in the steady state. If the capital rental rate is identical, the price per unit labor must be identical in both countries in the steady state as well. The factor prices are therefore written without a country index in the following.

The per unit costs for a variety of good $X$ can accordingly be written as:

$$
c_{X}=w^{\xi} \cdot r^{1-\xi}, \quad \text { with } \xi=\phi_{1} \cdot \alpha+\phi_{2} \cdot(1-\alpha) .
$$

\footnotetext{
${ }^{9}$ Note that the factor market equilibrium conditions are non-linear in factor prices if, e.g., Cobb-Douglas production technologies are assumed. Therefore, in a static setup, in which the equilibrium factor price ratio has to be determined by the factor market equilibrium conditions, analytical solutions are typically not available.
} 


\subsection{Horizontal versus vertical multinational firms}

\subsubsection{Horizontal multinational firms}

A single horizontal multinational firm with headquarters in country $i, i=H, F$, has two production plants, one in country $H$ and one in country $F$. Each production plant produces both intermediate goods $v_{1}$ and $v_{2}$ and assembles them to a unique variety of good $X$. Since each production plant produces a unique variety of good $X$, the final output of each production plant is sold domestically and exported to the other country.

Note that a single horizontal multinational firm sells two unique varieties of good $X$ since it owns two production plants.

Chart 1 of figure 1 illustrates the allocation of production activities across countries for horizontal multinational firms. The arrows from headquarter services (HQS) to both production plants $(\mathrm{PP})$ indicate that headquarter services are produced in one country, but supplied to the production plants in both countries.

\subsubsection{Vertical multinational firms}

A single vertical multinational firm with headquarters in country $i, i=H, F$, has two production plants as well, one in country $H$ and one in country $F$. However, each production plant produces only either intermediate good $v_{1}$ or intermediate good $v_{2}$. Since vertical multinational firms typically have an identical allocation of production activities across countries (e.g., Markusen, 2002), it is assumed that intermediate good $v_{1}$ is only produced by production plants in country $\mathrm{H}$ and intermediate good $v_{2}$ is only produced by production plants in country $F$.

Therefore, the production plants in country $H$ import intermediate good $v_{2}$ and the production plants in country $F$ import intermediate good $v_{1}$. Each production plant then assembles both intermediate goods to a unique variety of good $X$. Since each production plant produces a unique variety of good $X$, each production plant sells its variety both domestically and to the other country.

Note again that a single vertical multinational firm sells two unique varieties of good $X$ since it owns two production plants.

Charts 2 and 3 of figure 1 illustrate the allocation of production activities across countries for vertical multinational firms. 


\subsection{Demand}

The household's utility in country $i$ in a single period of the steady state is given by:

$$
\begin{aligned}
& U_{i}=X_{i}^{\gamma_{i}} \cdot Z_{i}^{1-\gamma_{i}}, \quad 0 \leq \gamma_{i} \leq 1, \\
& \text { with } \quad X_{i}=\left[\left(N_{H}+N_{F}\right) \cdot X_{i i}^{(\sigma-1) / \sigma}+\left(N_{H}+N_{F}\right) \cdot X_{j i}^{(\sigma-1) / \sigma}\right]^{\sigma /(\sigma-1)}, \quad \sigma>1 \\
& \quad \text { and } \quad Z_{i}=Z_{i i}+Z_{j i} .
\end{aligned}
$$

$\sigma$ stands for the elasticity of substitution between any two varieties of good $X$ and $N_{H}$ and $N_{F}$ stand for the number of multinational firms with headquarters in country $H$ and $F$. Whether these firms are horizontal or vertical multinational firms is determined exogenously later, when the general steady state equilibrium is derived. $X_{i i}$ stands for the supply of a production plant from country $i$ to country $i . X_{j i}$ stands for the supply of a production plant from country $j$ to country $i$. Similarly, $Z_{i i}$ stands for the supply of good $Z$ from country $i$ to country $i$ and $Z_{j i}$ stands for the supply of good $Z$ from country $j$ to country $i$.

It is assumed that the sum $N_{H}+N_{F}$ is sufficiently large so that the market for good $X$ is characterized by large-group monopolistic competition. Profit maximizing sector $X$ firms then supply their unique varieties of $\operatorname{good} X$ at price $p_{X}=\frac{\sigma}{\sigma-1} \cdot c_{X}$. Since factor prices are identical in both countries in the steady state, $c_{X}$ does not have a country index.

The price index which is dual to the CES-aggregate $X_{i}$ is then given by:

$$
\begin{aligned}
P & =\left[\left(N_{H}+N_{F}\right) \cdot p_{X}^{1-\sigma}+\left(N_{H}+N_{F}\right) \cdot p_{X}^{1-\sigma}\right]^{1 /(1-\sigma)} \\
& =\left(N_{H}+N_{F}\right)^{1 /(1-\sigma)} \cdot \frac{\sigma}{\sigma-1} \cdot w^{\xi} \cdot r^{1-\xi} \cdot 2^{1 /(1-\sigma)} .
\end{aligned}
$$

If

$$
M_{i}=L_{i} \cdot w+K_{i} \cdot r
$$

denotes aggregate factor income of country $i, i=H, F$, the supply $=$ demand-conditions for a variety of good $X$ result as:

$$
\begin{aligned}
X_{i i} & =p_{X}^{-\sigma} \cdot P^{\sigma-1} \cdot M_{i} \cdot \gamma_{i}=\left(\frac{\sigma}{\sigma-1} \cdot w^{\xi} \cdot r^{1-\xi}\right)^{-\sigma} \cdot \frac{\left(\frac{\sigma}{\sigma-1} \cdot w^{\xi} \cdot r^{1-\xi}\right)^{\sigma-1}}{2 \cdot\left(N_{H}+N_{F}\right)} \cdot M_{i} \cdot \gamma_{i} \\
& =\gamma_{i} \cdot \frac{\sigma-1}{\sigma} \cdot \frac{1}{w^{\xi} \cdot r^{1-\xi}} \cdot \frac{M_{i}}{2 \cdot\left(N_{H}+N_{F}\right)}, \quad i=H, F
\end{aligned}
$$

and, similarly,

$$
X_{i j}=\gamma_{j} \cdot \frac{\sigma-1}{\sigma} \cdot \frac{1}{w^{\xi} \cdot r^{1-\xi}} \cdot \frac{M_{j}}{2 \cdot\left(N_{H}+N_{F}\right)}, \quad i, j=H, F, \quad i \neq j .
$$

Note that the left-hand sides of equations (22) and (23) denote the supply of a single production plant from country $i$ to country $i$ or $j$. The right-hand sides of equations (22) and 
(23) accordingly denote the demand in country $i$ or $j$ for a unique variety which is produced by a production plant from country $i$.

The supply $=$ demand-condition for good $Z$ and country $i$ can be derived as:

$$
Z_{i i}+Z_{j i}=\frac{M_{i}}{p_{Z}} \cdot\left(1-\gamma_{i}\right), \quad i, j=H, F, \quad i \neq j .
$$

\subsection{Free entry condition}

If entry into sector $X$ is unrestricted, the free entry condition for sector $X$ has to hold in each period of the steady state. The free entry condition sets total markup revenue of a single multinational firm equal to total fixed costs of this firm. The free entry condition of a single multinational firm is given by:

$$
\left(p_{X}-c_{X}\right) \cdot\left(X_{H H}+X_{H F}+X_{F F}+X_{F H}\right)=r \cdot\left(F_{H Q S+P P}+F_{P P}\right),
$$

where the left-hand side of equation (25) denotes total markup revenue of a single multinational firm and the right-hand side of equation (25) denotes total fixed costs of this firm.

$p_{X}-c_{X}$ stands for the markup revenue per unit of good $X$ sales. The sum $X_{H H}+X_{H F}$ denotes total sales of the firm's production plant in country $H$ and the sum $X_{F F}+X_{F H}$ denotes total sales of the firm's production plant in country $F$. $F_{H Q S+P P}$ stands for the fixed capital input in the country of the firm's headquarters. $F_{H Q S+P P}$ is used for running the entire firm, i.e. for producing headquarter services (HQS), and for maintaining the production plant $(\mathrm{PP})$ in the country of the firm's headquarters. $F_{P P}$ stands for the fixed capital input in the host country. $F_{P P}$ is used for maintaining the production plant in the host country. The term $r \cdot\left(F_{H Q S+P P}+F_{P P}\right)$ accordingly denotes total fixed costs of a single multinational firm.

Substituting the expressions for $X_{H H}, X_{H F}, X_{F F}$ and $X_{F H}$ (equations (22) and (23)) into equation (25) and considering that $p_{X}=\frac{\sigma}{\sigma-1} \cdot c_{X}=\frac{\sigma}{\sigma-1} \cdot w^{\xi} \cdot r^{1-\xi}$ leads to the following simplification of the free entry condition:

$$
\frac{M_{H} \cdot \gamma_{H}+M_{F} \cdot \gamma_{F}}{\sigma \cdot\left(N_{H}+N_{F}\right)}=r \cdot\left(F_{H Q S+P P}+F_{P P}\right)
$$

\subsection{Trade balance equation}

The trade pattern between countries depends on whether horizontal or vertical multinational firms are active. In the regime with horizontal multinational firms, countries only trade the varieties of the differentiated good $X$ and good $Z .{ }^{10}$ In the regime with vertical multinational

\footnotetext{
${ }^{10}$ Note that the varieties of good $X$ are traded even between completely identical countries due to DixitStiglitz preferences for good $X$ (e.g., Markusen and Venables, 2000). Good $Z$ is only traded if trade in the varieties of good $X$ is not balanced.
} 
firms, countries additionally trade intermediate goods $v_{1}$ and $v_{2} \cdot{ }^{11}$

The trade balance equation is therefore derived separately for either firm regime.

\subsubsection{Trade balance equation with horizontal multinational firms}

Trade between countries $H$ and $F$ is balanced if the value of exports equals the value of imports, i.e. if the following holds:

$$
Z_{H F} \cdot p_{Z}+\left(N_{H}+N_{F}\right) \cdot X_{H F} \cdot p_{X}=Z_{F H} \cdot p_{Z}+\left(N_{H}+N_{F}\right) \cdot X_{F H} \cdot p_{X} .
$$

The left-hand side (right-hand side) of equation (27) denotes the value of country $H$ 's exports (imports). Since $X_{H F}$ and $X_{F H}$ stand for exports of a single production plant from country $H$ and $F$, the quantities $X_{H F}$ and $X_{F H}$ have to be multiplied by $N_{H}+N_{F}$. The sum $N_{H}+N_{F}$ denotes the total number of firms and each firm owns a production plant in each country.

Considering that country $H$ 's imports of good $Z$ are country $F$ 's exports of good $Z$, the variable $Z_{F H}$ can be set equal to zero and $Z_{H F}$ is allowed to be negative. Substituting the expressions for $X_{H F}$ and $X_{F H}$ (equation (23)) into equation (27), considering $p_{Z}=w^{\beta} \cdot r^{1-\beta}$ and $p_{X}=\frac{\sigma}{\sigma-1} \cdot w^{\xi} \cdot r^{1-\xi}$ and simplification leads to the following expressions for the trade balance equation:

$$
Z_{H F}=\frac{M_{H} \cdot \gamma_{H}-M_{F} \cdot \gamma_{F}}{2 \cdot w^{\beta} \cdot r^{1-\beta}}
$$

\subsubsection{Trade balance equation with vertical multinational firms}

Trade of intermediate goods between countries has to be considered as well in this firm regime.

Country $H$ 's imports of intermediate good $v_{2}$ are equal to:

$$
\frac{\partial c_{X}}{\partial c_{v_{2}}} \cdot\left(X_{H H}+X_{H F}\right) \cdot\left(N_{H}+N_{F}\right) .
$$

$\frac{\partial c_{X}}{\partial c_{v_{2}}}$ denotes the input of intermediate good $v_{2}$ per unit of good $X$ due to Shephard's Lemma. $\left(X_{H H}+X_{H F}\right) \cdot\left(N_{H}+N_{F}\right)$ denotes total production of good $X$ in country $H$. Considering equations (5) and (7), $\frac{\partial c_{X}}{\partial c_{v_{2}}}$ can be calculated as:

$$
\frac{\partial c_{X}}{\partial c_{v_{2}}}=(1-\alpha) \cdot\left(\frac{c_{v_{1}}}{c_{v_{2}}}\right)^{\alpha}=(1-\alpha) \cdot\left(\frac{w_{H}^{\phi_{1}} \cdot r_{H}^{1-\phi_{1}}}{w_{F}^{\phi_{2}} \cdot r_{F}^{1-\phi_{2}}}\right)^{\alpha}=(1-\alpha) \cdot\left(\frac{w}{r}\right)^{\alpha \cdot\left(\phi_{1}-\phi_{2}\right)}
$$

where the last equality uses the fact that factor prices are identical in both countries in the steady state with free trade.

\footnotetext{
${ }^{11}$ Strictly speaking, intermediate goods $v_{1}$ and $v_{2}$ are traded within the firm. However, production of intermediate goods leads to factor income, which leads to demand for final goods in the country of production. Trade of intermediate goods therefore has to be considered as well in the trade balance equation.
} 
Similarly, country $F$ 's imports of intermediate good $v_{1}$ are equal to:

$$
\frac{\partial c_{X}}{\partial c_{v_{1}}} \cdot\left(X_{F F}+X_{F H}\right) \cdot\left(N_{H}+N_{F}\right) .
$$

Again, $\frac{\partial c_{X}}{\partial c_{v_{1}}}$ denotes the input of intermediate good $v_{1}$ per unit of good $X$ due to Shephard's Lemma and $\left(X_{F F}+X_{F H}\right) \cdot\left(N_{H}+N_{F}\right)$ denotes total production of good $X$ in country $F$. Considering equations (5) and (7), $\frac{\partial c_{X}}{\partial c_{v_{1}}}$ results as:

$$
\frac{\partial c_{X}}{\partial c_{v_{1}}}=\alpha \cdot\left(\frac{c_{v_{2}}}{c_{v_{1}}}\right)^{1-\alpha}=\alpha \cdot\left(\frac{w_{F}^{\phi_{2}} \cdot r_{F}^{1-\phi_{2}}}{w_{H}^{\phi_{1}} \cdot r_{H}^{1-\phi_{1}}}\right)^{1-\alpha}=\alpha \cdot\left(\frac{w}{r}\right)^{(1-\alpha) \cdot\left(\phi_{2}-\phi_{1}\right)} .
$$

The trade balance equation in the regime with vertical multinational firms accordingly results as follows:

$$
\begin{aligned}
& Z_{H F} \cdot p_{Z}+\left[\alpha \cdot\left(\frac{w}{r}\right)^{(1-\alpha) \cdot\left(\phi_{2}-\phi_{1}\right)} \cdot\left(X_{F F}+X_{F H}\right) \cdot w^{\phi_{1}} \cdot r^{1-\phi_{1}}+X_{H F} \cdot p_{X}\right] \cdot\left(N_{H}+N_{F}\right) \\
& =Z_{F H} \cdot p_{Z}+\left[(1-\alpha) \cdot\left(\frac{w}{r}\right)^{\alpha \cdot\left(\phi_{1}-\phi_{2}\right)} \cdot\left(X_{H H}+X_{H F}\right) \cdot w^{\phi_{2}} \cdot r^{1-\phi_{2}}+X_{F H} \cdot p_{X}\right] \cdot\left(N_{H}+N_{F}\right) .
\end{aligned}
$$

Again, $Z_{F H}$ is set equal to zero and $Z_{H F}$ is allowed to be negative since country $H$ 's imports of good $Z$ are equal to country $F$ 's exports of good $Z$. Substituting the expressions for $X_{H H}$, $X_{F F}, X_{H F}$ and $X_{F H}$ (equations (22) and (23)) into equation (33), considering $p_{Z}=w^{\beta} \cdot r^{1-\beta}$ and $p_{X}=\frac{\sigma}{\sigma-1} \cdot w^{\xi} \cdot r^{1-\xi}$ and simplification leads to the following expression for the trade balance equation:

$$
Z_{H F}=\frac{\sigma-1}{\sigma} \cdot \frac{M_{H} \cdot \gamma_{H}+M_{F} \cdot \gamma_{F}}{2 \cdot w^{\beta} \cdot r^{1-\beta}} \cdot(1-2 \cdot \alpha)+\frac{M_{H} \cdot \gamma_{H}-M_{F} \cdot \gamma_{F}}{2 \cdot w^{\beta} \cdot r^{1-\beta}} .
$$

\section{General steady state equilibrium}

The general steady state equilibrium for this 2-country world is characterized by:

1. the condition $\frac{w}{r}=(\rho+\delta)^{-1 / \beta}$ since countries are in the steady state (equation (15))

2. the supply $=$ demand conditions for each variety of good $X$ (equations (22) and (23))

3. the free entry condition for sector $X$ (equation (26))

4. the trade balance equation (equation (28) or equation (34))

5. two factor market equilibrium conditions for each country.

Conditions 1.-4. can be substituted into the two factor market equilibrium conditions for each country. The general steady state equilibrium for this 2 -country world can then be 
represented by a system of four equations, which are linear in four variables. The four variables are the numbers of multinational firms $N_{H}$ and $N_{F}$ and the countries' capital endowments $K_{H}$ and $K_{F}$ in the steady state.

If $N_{H}, N_{F}, K_{H}$ and $K_{F}$ are known and if one production factor, e.g., labor in country $H$, is chosen as the numéraire good, the steady state values of all quantity variables and relative prices can be derived:

- the relative price of capital follows from equation (15);

- the relative prices of intermediate goods $v_{1}$ and $v_{2}$ follow from equation (5), the relative prices of the final goods $Z$ and $X$ follow from equations (2) and (18);

- aggregate factor income in both countries follows from equation (21);

- demand for the varieties of good $X$ follows from equations (22) and (23), aggregate demand for good $\mathrm{Z}$ follows from equation (24);

- trade in the varieties of good $X$ follows from equation (23), trade in good $Z$ follows from equation (28) or equation (34);

- trade in intermediate goods $v_{1}$ and $v_{2}$ in the regime with vertical multinational activity follows from equations (29) and (31);

- finally, utility of either country follows from substituting the consumed quantities into equation (19).

Since horizontal and vertical multinational firms have different production patterns, the factor market equilibrium conditions differ between both firm regimes. Therefore, the general steady state equilibrium is derived separately for both firm regimes.

In order to simplify the setup of the general steady state equilibrium, the capital depreciation rate $\delta$ is normalized to zero. Since each country's labor endowment is assumed to be constant over time, investment in the steady state is therefore equal to zero as well. If a persistent exogenous shock in the comparative steady state analysis shifts the country to a new steady state with a larger (smaller) capital stock, investment is temporarily positive (negative).

\subsection{Horizontal multinational firms}

Horizontal multinational firms produce both intermediate goods $v_{1}$ and $v_{2}$ in each production plant. The per unit costs of good $X$ are accordingly given by:

$$
c_{X}\left(w_{i}, r_{i}\right)=w_{i}^{\phi_{1} \cdot \alpha} \cdot w_{i}^{\phi_{2} \cdot(1-\alpha)} \cdot r_{i}^{\left(1-\phi_{1}\right) \cdot \alpha} \cdot r_{i}^{\left(1-\phi_{2}\right) \cdot(1-\alpha)}=w^{\xi} \cdot r^{1-\xi},
$$


with $\xi=\phi_{1} \cdot \alpha+\phi_{2} \cdot(1-\alpha)$.

Applying Shephard's Lemma, the factor input coefficients for labor and capital into good $X$, $a_{L}^{X}(w, r)$ and $a_{K}^{X}(w, r)$, result as:

$$
a_{L}^{X}(w, r) \equiv \frac{\partial c_{X}(w, r)}{\partial w}=\xi \cdot\left(\frac{r}{w}\right)^{1-\xi} \quad \text { and } \quad a_{K}^{X}(w, r) \equiv \frac{\partial c_{X}(w, r)}{\partial r}=(1-\xi) \cdot\left(\frac{w}{r}\right)^{\xi} .
$$

The corresponding factor input coefficients for good $Z$ are given by:

$$
a_{L}^{Z}(w, r) \equiv \frac{\partial c_{Z}(w, r)}{\partial w}=\beta \cdot\left(\frac{r}{w}\right)^{1-\beta} \quad \text { and } \quad a_{K}^{Z}(w, r) \equiv \frac{\partial c_{Z}(w, r)}{\partial r}=(1-\beta) \cdot\left(\frac{w}{r}\right)^{\beta} .
$$

The factor input coefficients $a_{L}^{X}(w, r), a_{K}^{X}(w, r), a_{L}^{Z}(w, r)$ and $a_{K}^{Z}(w, r)$ are used to derive the factor market equilibrium conditions for either country. Note that $N_{H}$ and $N_{F}$ stand for the mass of active horizontal multinational firms, $X_{H H}, X_{H F}, X_{F F}$ and $X_{F H}$ stand for the supply of a single horizontal multinational firm and $N_{i} \cdot F_{H Q S+P P}$ and $N_{j} \cdot F_{P P}, i, j=H, F$, stand for the capital demand for producing fixed costs:

equilibrium on labor market of country $H$ :

$$
\xi \cdot\left(\frac{r}{w}\right)^{1-\xi} \cdot\left(X_{H H}+X_{H F}\right) \cdot\left(N_{H}+N_{F}\right)+\beta \cdot\left(\frac{r}{w}\right)^{1-\beta} \cdot\left(Z_{H H}+Z_{H F}\right)=L_{H}
$$

equilibrium on capital market of country $H$ :

$$
\begin{aligned}
(1-\xi) \cdot & \left(\frac{w}{r}\right)^{\xi} \cdot\left(X_{H H}+X_{H F}\right) \cdot\left(N_{H}+N_{F}\right) \\
& \quad+N_{H} \cdot F_{H Q S+P P}+N_{F} \cdot F_{P P}+(1-\beta) \cdot\left(\frac{w}{r}\right)^{\beta} \cdot\left(Z_{H H}+Z_{H F}\right)=K_{H}
\end{aligned}
$$

equilibrium on labor market of country F:

$$
\xi \cdot\left(\frac{r}{w}\right)^{1-\xi} \cdot\left(X_{F F}+X_{F H}\right) \cdot\left(N_{H}+N_{F}\right)+\beta \cdot\left(\frac{r}{w}\right)^{1-\beta} \cdot Z_{F F}=L_{F}
$$

equilibrium on capital market of country F:

$$
\begin{aligned}
(1-\xi) \cdot\left(\frac{w}{r}\right)^{\xi} \cdot( & \left.X_{F F}+X_{F H}\right) \cdot\left(N_{H}+N_{F}\right) \\
& +N_{H} \cdot F_{P P}+N_{F} \cdot F_{H Q S+P P}+(1-\beta) \cdot\left(\frac{w}{r}\right)^{\beta} \cdot Z_{F F}=K_{F} .
\end{aligned}
$$

Substituting the expressions for $X_{H H}, X_{H F}, X_{F F}$ and $X_{F H}$ (equations (22) and (23)) into the factor market equilibrium conditions, considering the free entry condition (equation (26)) 
and the trade balance equation (equation (28)) leads to the following simplification of the factor market equilibrium conditions:

$$
\begin{gathered}
\xi \cdot \frac{\sigma-1}{2} \cdot \frac{r}{w} \cdot\left(F_{H Q S+P P}+F_{P P}\right) \cdot\left(N_{H}+N_{F}\right) \\
+\frac{M_{H}}{w} \cdot \beta \cdot\left(1-\frac{\gamma_{H}}{2}\right)+\frac{M_{F}}{w} \cdot \beta \cdot \frac{-\gamma_{F}}{2}=L_{H} \\
(1-\xi) \cdot \frac{\sigma-1}{2} \cdot \frac{r}{w} \cdot\left(F_{H Q S+P P}+F_{P P}\right) \cdot\left(N_{H}+N_{F}\right)+N_{H} \cdot \frac{r}{w} \cdot F_{H Q S+P P}+N_{F} \cdot \frac{r}{w} \cdot F_{P P} \\
+\frac{M_{H}}{w} \cdot(1-\beta) \cdot\left(1-\frac{\gamma_{H}}{2}\right)+\frac{M_{F}}{w} \cdot(1-\beta) \cdot \frac{-\gamma_{F}}{2}=\frac{r}{w} \cdot K_{H} \\
\quad+\frac{M_{H}}{w} \cdot \beta \cdot \frac{-\gamma_{H}}{2}+\frac{M_{F}}{w} \cdot \beta \cdot\left(1-\frac{\gamma_{F}}{2}\right)=L_{F} \\
\xi \cdot \frac{\sigma-1}{2} \cdot \frac{r}{w} \cdot\left(F_{H Q S+P P}+F_{P P}\right) \cdot\left(N_{H}+N_{F}\right) \\
(1-\xi) \cdot \frac{\sigma-1}{2} \cdot \frac{r}{w} \cdot\left(F_{H Q S+P P}+F_{P P}\right) \cdot\left(N_{H}+N_{F}\right)+N_{H} \cdot \frac{r}{w} \cdot F_{P P}+N_{F} \cdot \frac{r}{w} \cdot F_{H Q S+P P} \\
+\frac{M_{H}}{w} \cdot(1-\beta) \cdot \frac{-\gamma_{H}}{2}+\frac{M_{F}}{w} \cdot(1-\beta) \cdot\left(1-\frac{\gamma_{F}}{2}\right)=\frac{r}{w} \cdot K_{F} .
\end{gathered}
$$

Since the factor price ratio $\frac{r}{w}$ is already fixed by the parameters $\rho, \delta$ and $\beta$ in the steady state (equation (15)), equations (40)-(43) are linear in the four variables $N_{H}, N_{F}, K_{H}$ and $K_{F}$.

The steady state of this 2-country world, which is described by equations (40)-(43), is now disturbed by four different persistent exogenous shocks. The first shock is a symmetric demand shift in favor of good $X$, i.e. $d \gamma_{H}=d \gamma_{F}>0$. The second shock is a demand shift in favor of good $X$ only in country $H$, i.e. $d \gamma_{H}>0$ and $d \gamma_{F}=0 .{ }^{12}$ The third shock is a symmetric increase in population size, i.e. $d L_{H}=d L_{F}>0$. The fourth shock is an increase in population size only in country $H$, i.e. $d L_{H}>0$ and $d L_{F}=0$.

Note that these four shocks are the only relevant ones. ${ }^{13}$

\footnotetext{
${ }^{12}$ In order to keep the model analytically solvable, it is assumed that $\gamma_{H}=\gamma_{F}$ in the initial steady state as described by equations (40)-(43). If the initial steady state is disturbed by an asymmetric demand shift towards good $X$, we have $\gamma_{H} \neq \gamma_{F}$ in the new steady state.

${ }^{13}$ If the steady state were disturbed by an asymmetric shock in the production technologies, countries completely specialized in the production of either $\operatorname{good} X$ or good $Z$ (cf. Baxter, 1992). However, if there is complete specialization in production, no horizontal multinational firms, which produce good $X$ in both countries, do exist. If, alternatively, the steady state were disturbed by an asymmetric shock in the elasticity of substitution $\sigma$, the model were not analytically solvable any more. The reason is as follows: if $\sigma$ differs between countries, equation (26) becomes
}

$$
\left(\gamma_{H} \cdot \frac{M_{H}}{\sigma_{H}}+\gamma_{F} \cdot \frac{M_{F}}{\sigma_{F}}\right) \cdot\left(N_{H}+N_{F}\right)^{-1}=r \cdot\left(F_{H Q S+P P}+F_{P P}\right) .
$$


If the capital stocks of both countries, $K_{H}$ and $K_{F}$, move into the same direction due to the shock, i.e. if $\frac{d K_{H}}{d K_{F}}>0$, domestic and foreign investments are complements. If the capital stocks $K_{H}$ and $K_{F}$ move into opposite directions due to the shock, i.e. $\frac{d K_{H}}{d K_{F}}<0$, domestic and foreign investments are substitutes.

Based on the comparative steady state analysis, which is relegated to appendix A, we can derive hypotheses $\mathrm{H} 1$ and $\mathrm{H} 2$ on the relationship between $K_{H}$ and $K_{F}$ if multinational activity is horizontal:

H1: In the case of

- a symmetric demand shift $\left(d \gamma_{H}=d \gamma_{F}>0\right)$

- an asymmetric demand shift $\left(d \gamma_{H}>0\right.$ and $\left.d \gamma_{F}=0\right)$

- a symmetric increase in population size $\left(d L_{H}=d L_{F}>0\right)$

the domestic and the foreign capital stock are perfect complements with $\frac{d K_{H}}{d K_{F}}=1$.

H2: In the case of an asymmetric increase in population size $\left(d L_{H}>0\right.$ and $\left.d L_{F}=0\right)$ the domestic and the foreign capital stock are complements with $\frac{d K_{H}}{d K_{F}}>0$.

Proof: See appendix A.

The intuition for these results is as follows: in the case of horizontal multinational activity, multinational firms produce both intermediate goods $v_{1}$ and $v_{2}$ in both countries. The factor intensities of multinational production are therefore identical in both countries. Moreover, any of the considered shocks increases good $X$ production in both countries:

(i) A demand shift towards good $X\left(d \gamma_{H}=d \gamma_{F}>0\right.$ or $d \gamma_{H}>0$ and $\left.d \gamma_{F}=0\right)$ increases good $X$ production relative to good $Z$ production in both countries. ${ }^{14}$

(ii) A symmetric increase in population size $\left(d L_{H}=d L_{F}>0\right)$ increases production of goods $X$ and $Z$ in both countries proportionately.

However, the sum $X_{i i}+X_{i j}$ in the factor market equilibrium conditions equals

$$
\left(\frac{\sigma_{H}-1}{\sigma_{H}} \cdot \gamma_{H} \cdot M_{H}+\frac{\sigma_{F}-1}{\sigma_{F}} \cdot \gamma_{F} \cdot M_{F}\right) \cdot\left(N_{H}+N_{F}\right)^{-1}
$$

if $\sigma$ differs between countries. Therefore, $X_{i i}+X_{i j}$ in the factor market equilibrium conditions cannot be substituted by $r \cdot\left(F_{H Q S+P P}+F_{P P}\right) \cdot(\sigma-1)$ from equation (26) if $\sigma$ differs between countries. However, this substitution is necessary to get the factor market equilibrium conditions linear in $N_{H}$ and $N_{F}$ like in equations (40)-(43).

${ }^{14}$ Note that also an asymmetric demand shock increases good $X$ production in both countries since households demand varieties from both countries due to Dixit-Stiglitz preferences. 
(iii) An asymmetric increase in population size $\left(d L_{H}>0\right.$ and $\left.d L_{F}=0\right)$ increases production of goods $X$ and $Z$ in country $H$ proportionately and it increases production of good $X$ in country $F$ since country $H$ increases its imports of good $X$.

In either case demand for capital increases in both countries since good $X$ is capital intensive relative to good $Z$. The increase in capital demand increases the steady state capital stock in both countries.

\subsection{Vertical multinational firms}

Vertical multinational firms produce intermediate good $v_{1}$ in their production plant in country $H$ and intermediate good $v_{2}$ in their production plant in country $F$. The per unit costs of good $X$ are accordingly given by:

$$
c_{X}\left(w_{H}, w_{F}, r_{H}, r_{F}\right)=w_{H}^{\phi_{1} \cdot \alpha} \cdot w_{F}^{\phi_{2} \cdot(1-\alpha)} \cdot r_{H}^{\left(1-\phi_{1}\right) \cdot \alpha} \cdot r_{F}^{\left(1-\phi_{2}\right) \cdot(1-\alpha)} .
$$

Applying Shephard's Lemma and considering afterwards factor price equalization in the steady state, the factor input coefficients for good $X$, which are given by $a_{L, i}^{X}\left(w_{H}, w_{F}, r_{H}, r_{F}\right)$ and $a_{K, i}^{X}\left(w_{H}, w_{F}, r_{H}, r_{F}\right), i=H, F$, can be derived as:

$$
\begin{aligned}
& a_{L H}^{X}\left(w_{H}, w_{F}, r_{H}, r_{F}\right) \equiv \frac{\partial c_{X}\left(w_{H}, w_{F}, r_{H}, r_{F}\right)}{\partial w_{H}}=\phi_{1} \cdot \alpha \cdot\left(\frac{r}{w}\right)^{1-\xi}, \\
& a_{K H}^{X}\left(w_{H}, w_{F}, r_{H}, r_{F}\right) \equiv \frac{\partial c_{X}\left(w_{H}, w_{F}, r_{H}, r_{F}\right)}{\partial r_{H}}=\left(1-\phi_{1}\right) \cdot \alpha \cdot\left(\frac{w}{r}\right)^{\xi}, \\
& a_{L F}^{X}\left(w_{H}, w_{F}, r_{H}, r_{F}\right) \equiv \frac{\partial c_{X}\left(w_{H}, w_{F}, r_{H}, r_{F}\right)}{\partial w_{F}}=\phi_{2} \cdot(1-\alpha) \cdot\left(\frac{r}{w}\right)^{1-\xi} \text { and } \\
& a_{K F}^{X}\left(w_{H}, w_{F}, r_{H}, r_{F}\right) \equiv \frac{\partial c_{X}\left(w_{H}, w_{F}, r_{H}, r_{F}\right)}{\partial r_{F}}=\left(1-\phi_{2}\right) \cdot(1-\alpha) \cdot\left(\frac{w}{r}\right)^{\xi},
\end{aligned}
$$

with $\xi=\phi_{1} \cdot \alpha+\phi_{2} \cdot(1-\alpha)$. Again, the corresponding factor input coefficients for good $Z$ are given by:

$$
a_{L}^{Z}(w, r) \equiv \frac{\partial c_{Z}(w, r)}{\partial w}=\beta \cdot\left(\frac{r}{w}\right)^{1-\beta} \quad \text { and } \quad a_{K}^{Z}(w, r) \equiv \frac{\partial c_{Z}(w, r)}{\partial r}=(1-\beta) \cdot\left(\frac{w}{r}\right)^{\beta} .
$$

These factor input coefficients are used to derive the factor market equilibrium conditions for either country. $N_{H}$ and $N_{F}$ now stand for the mass of active vertical multinational firms and $X_{H H}, X_{H F}, X_{F F}, X_{F H}$ stand for the supply of a single vertical multinational firm:

equilibrium on labor market of country $H$ :

$$
\phi_{1} \cdot \alpha \cdot\left(\frac{r}{w}\right)^{1-\xi} \cdot\left(X_{H H}+X_{H F}\right) \cdot\left(N_{H}+N_{F}\right)+\beta \cdot\left(\frac{r}{w}\right)^{1-\beta} \cdot\left(Z_{H H}+Z_{H F}\right)=L_{H}
$$


equilibrium on capital market of country $H$ :

$$
\begin{aligned}
\left(1-\phi_{1}\right) \cdot \alpha \cdot\left(\frac{w}{r}\right)^{\xi} \cdot\left(X_{H H}+X_{H F}\right) \cdot\left(N_{H}+N_{F}\right) \\
\quad+N_{H} \cdot F_{H Q S+P P}+N_{F} \cdot F_{P P}+(1-\beta) \cdot\left(\frac{w}{r}\right)^{\beta} \cdot\left(Z_{H H}+Z_{H F}\right)=K_{H}
\end{aligned}
$$

equilibrium on labor market of country F:

$$
\phi_{2} \cdot(1-\alpha) \cdot\left(\frac{r}{w}\right)^{1-\xi} \cdot\left(X_{F F}+X_{F H}\right) \cdot\left(N_{H}+N_{F}\right)+\beta \cdot\left(\frac{r}{w}\right)^{1-\beta} \cdot Z_{F F}=L_{F}
$$

equilibrium on capital market of country $F$ :

$$
\begin{aligned}
\left(1-\phi_{2}\right) \cdot(1-\alpha) & \cdot\left(\frac{w}{r}\right)^{\xi} \cdot\left(X_{F F}+X_{F H}\right) \cdot\left(N_{H}+N_{F}\right) \\
& +N_{H} \cdot F_{P P}+N_{F} \cdot F_{H Q S+P P}+(1-\beta) \cdot\left(\frac{w}{r}\right)^{\beta} \cdot Z_{F F}=K_{F} .
\end{aligned}
$$

Substituting the expressions for $X_{H H}, X_{H F}, X_{F F}$ and $X_{F H}$ (equations (22) and (23)) into the factor market equilibrium conditions, considering the free entry condition (equation (26)) and the trade balance equation (equation (34)) leads to the following simplification of the factor market equilibrium conditions:

$$
\begin{gathered}
\phi_{1} \cdot \alpha \cdot \frac{\sigma-1}{2} \cdot \frac{r}{w} \cdot\left(F_{H Q S+P P}+F_{P P}\right) \cdot\left(N_{H}+N_{F}\right) \\
+\frac{M_{H}}{w} \cdot \beta \cdot\left(1-\frac{\gamma_{H}}{2} \cdot \frac{2 \cdot \alpha \cdot(\sigma-1)+1}{\sigma}\right)+\frac{M_{F}}{w} \cdot \beta \cdot \frac{\gamma_{F}}{2} \cdot \frac{2 \cdot \alpha \cdot(1-\sigma)-1}{\sigma}=L_{H}(49) \\
\left(1-\phi_{1}\right) \cdot \alpha \cdot \frac{\sigma-1}{2} \cdot \frac{r}{w} \cdot\left(F_{H Q S+P P}+F_{P P}\right) \cdot\left(N_{H}+N_{F}\right)+N_{H} \cdot \frac{r}{w} \cdot F_{H Q S+P P}+N_{F} \cdot \frac{r}{w} \cdot F_{P P} \\
+\frac{M_{H}}{w} \cdot(1-\beta) \cdot\left(1-\frac{2 \cdot \alpha \cdot(\sigma-1)+1}{2 \cdot \sigma / \gamma_{H}}\right)+\frac{M_{F}}{w} \cdot(1-\beta) \cdot \frac{2 \cdot \alpha \cdot(1-\sigma)-1}{2 \cdot \sigma / \gamma_{F}}=\frac{r}{w} \cdot K_{H}(50) \\
+\frac{M_{H}}{w} \cdot \beta \cdot \frac{1-2 \cdot \alpha-2 \cdot \sigma \cdot(1-\alpha)}{2 \cdot \sigma / \gamma_{H}}+\frac{M_{F}}{w} \cdot \beta \cdot\left(1-\frac{2 \cdot \alpha-1+2 \cdot \sigma \cdot(1-\alpha)}{2 \cdot \sigma / \gamma_{F}}\right)=L_{F}(51) \\
\left(1-\phi_{2}\right) \cdot(1-\alpha) \cdot \frac{\sigma-1}{2} \cdot \frac{r}{w} \cdot\left(F_{H Q S+P P}+F_{P P}\right) \cdot\left(N_{H}+N_{F}\right)+N_{F} \cdot \frac{r}{w} \cdot F_{H Q S+P P}+N_{H} \cdot \frac{r}{w} \cdot F_{P P} \\
+\frac{M_{H}}{w} \cdot(1-\beta) \cdot \frac{1-2 \cdot \alpha-2 \cdot \sigma \cdot(1-\alpha)}{2 \cdot \sigma / \gamma_{H}}+\frac{M_{F}}{w} \cdot(1-\beta) \cdot\left(1-\frac{2 \cdot \alpha-1+2 \cdot \sigma \cdot(1-\alpha)}{2 \cdot \sigma / \gamma_{F}}\right)=\frac{r}{w} \cdot K_{F} \cdot(52)
\end{gathered}
$$

Again, since the factor price ratio $\frac{r}{w}$ is fixed by the parameters $\rho, \delta$ and $\beta$ in the steady state (equation (15)), equations (49)-(52) are linear in the four variables $N_{H}, N_{F}, K_{H}$ and $K_{F}$. 
The steady state in the 2-country world with vertical multinational activity is described by equations (49)-(52). ${ }^{15}$

In order to analyze whether vertical multinational activity leads to a different relationship between the capital stocks $K_{H}$ and $K_{F}$, compared to horizontal multinational activity, the steady state with vertical multinational activity is disturbed by the same four persistent exogenous shocks as before.

The comparative steady state analysis for vertical multinational activity is relegated to appendix B. The relationship between the capital stocks $K_{H}$ and $K_{F}$ in the regime with vertical multinational activity is summarized by hypothesis $\mathrm{H} 3$ :

H3: In the case of

- a symmetric demand shift $\left(d \gamma_{H}=d \gamma_{F}>0\right)$

- an asymmetric demand shift $\left(d \gamma_{H}>0\right.$ and $\left.d \gamma_{F}=0\right)$

- a symmetric increase in country size $\left(d L_{H}=d L_{F}>0\right)$

- an asymmetric increase in country size $\left(d L_{H}>0\right.$ and $\left.d L_{F}=0\right)$

the domestic and the foreign capital stock are substitutes, i.e. $\frac{d K_{H}}{d K_{F}}<0$ if:

- the labor share of intermediate good $v_{1}$, which is produced in country $H$, is sufficiently small, i.e. if $\phi_{1}$ is sufficiently small

- the share of intermediate good $v_{1}$ in final goods production is sufficiently small, i.e. if $\alpha$ is sufficiently small.

If $\phi_{1}$ and $\alpha$ are not sufficiently small, the domestic and the foreign capital stock are complements, i.e. $\frac{d K_{H}}{d K_{F}}>0$.

Proof: See appendix B.

The intuition for these results is as follows: in the case of vertical multinational activity, multinational firms produce the capital intensive intermediate good $v_{1}$ in country $H$ and the labor intensive intermediate good $v_{2}$ in country $F$. The factor intensities of multinational production therefore differ between countries.

In the case of a demand shift towards good $X\left(d \gamma_{H}=d \gamma_{F}>0\right.$ or $d \gamma_{H}>0$ and $d \gamma_{F}=$ 0 ), country $H$ increases $v_{1}$ production and country $F$ increases $v_{2}$ production. Aggregate

\footnotetext{
${ }^{15}$ It can be shown that the steady state capital stock $K_{F}$ is positive only if $L_{F}$ is sufficiently large relative to $L_{H}$. Therefore, the exogenous allocation of the capital-intensive (labor-intensive) intermediate good $v_{1}$ $\left(v_{2}\right)$ to country $H(F)$ only leads to a well-defined steady state if the exogenous labor endowments are chosen appropriately.
} 
production in country $H$ (country $F$ ) therefore becomes more capital (labor) intensive. The steady state capital stock in country $H$ (country $F$ ) therefore increases (decreases).

In the case of an increase in population size $\left(d L_{H}=d L_{F}>0\right.$ or $d L_{H}>0$ and $\left.d L_{F}=0\right)$, the intuition is most straightforward if $\alpha$ is close to 0.5 , i.e. if the term $1-2 \cdot \alpha$ is close to zero and if the term $\frac{M_{H} \cdot \gamma_{H}-M_{F} \cdot \gamma_{F}}{2 \cdot w^{\beta} \cdot r^{1-\beta}}$ dominates the trade balance equation (34). Two counteracting effects have to be considered:

(i) Both a symmetric and an asymmetric increase in population size ceteris paribus increase $K_{H}$ and $K_{F}$ since all production activities also use capital. However, the increase in $K_{H}$ is larger than the increase in $K_{F}$ since aggregate production in country $H$ is more capital intensive than aggregate production in country $F$. Therefore, $M_{H}$ increases by a larger amount than $M_{F}$, also in the case of a symmetric increase in population size.

(ii) Since $M_{H}$ increases by a larger amount than $M_{F}$, exports $Z_{H F}$ increase, i.e. country $F$ imports (exports) of good $Z$ (intermediate good $v_{2}$ ) increase. ${ }^{16}$ Since $v_{2}$ is labor intensive relative to $Z$, aggregate production in country $F$ becomes more labor intensive. This ceteris paribus decreases $K_{F}$ in the steady state.

If $\alpha$ is close to 0.5 and if the labor share parameter of $v_{2}$, which is given by $\phi_{2}=1-\phi_{1}$, is sufficiently large, the second effect dominates the first. $K_{F}$ then decrease with an increase in population size and $K_{H}$ and $K_{F}$ are substitutes.

If, in the extreme, $\phi_{1}=1-\phi_{2}=0.5$, the factor intensities of multinational activity are identical in both countries. The contrast between the vertical and horizontal multinational activity is absent in such a case and the domestic and the foreign capital stocks are complements.

Figure 2 summarizes the results of the comparative steady state analysis for the regime with horizontal multinational activity and the regime with vertical multinational activity.

\section{Empirical model}

Data for the empirical analysis are taken from the website of the Bureau of Economic Analysis (BEA). We constructed a panel with 42 sectors (see table A1 of the appendix), and 7 years (1999-2005). The BEA data divides the operations of multinational companies into the operation of the American parent company and its foreign affiliate(s). For the data of the foreign affiliates, the BEA allows to choose between data for majority-owned foreign affiliates only or all foreign affiliates, where the latter are defined as outward foreign direct investment

\footnotetext{
${ }^{16}$ Note that $Z_{H F}$ can also be negative; the absolute value of $Z_{H F}$ then becomes smaller and country $F$ exports less of good $Z$.
} 
with ownership or control by the parent firm of at least $10 \% .{ }^{17}$ We have chosen to use the data for the majority owned foreign affiliates. As initial year, 1999 is chosen since the BEA switched from SIC to the NAICS classification in that year.

In order to test the previously derived hypotheses, we construct four variables at the sector level: (i) Domestic Investment, defined as domestic capital expenditures of U.S. parent companies as part of total value added of U.S. parent companies; (ii) Foreign Investment, defined as foreign capital expenditures of U.S. parent companies as part of total value added of U.S. parent companies; (iii) Labor Share, defined as the total labor costs of U.S. affiliate firms as part of total value added of U.S. affiliate firms; (iv) Share Intermediate, defined as the exports of goods shipped from U.S. parents to foreign affiliates as part of the value added of the foreign affiliate firms. The last two variables are proxies for $\phi_{2}$ and $\alpha$, respectively, as defined in the previous theoretical part.

As to test differences in the relationship between domestic and foreign investment between horizontal and vertical MNEs, we make the assumption that MNEs in the manufacturing sectors are mainly vertical, while MNEs in other sectors are mainly horizontal. Table A1 of the appendix provides some motivation for this choice. It shows that average wages of affiliates in the manufacturing sectors are on average lower than in the non-manufacturing sectors. If we examine average wages of foreign affiliates over average wages of U.S. parent firms, the difference between both sector groups becomes more pronounced. This indicates that wage differences are more important for manufacturing sectors than for non-manufacturing sectors. Differences are most prevalent, however, when examining the exports shipped by U.S. parents to foreign affiliates. The mean of Share Intermediate, as shown in table A2 of the appendix, indicates that trade in intermediates is almost absent in many non-manufacturing industries, while exports of intermediates to affiliates constitutes around $43 \%$ of the value added of the affiliate firms in manufacturing industries. Therefore, the distinction between manufacturing and non-manufacturing seems to capture the main difference between vertical and horizontal MNEs remarkably well.

\subsection{Empirical results}

We test the implications of the theoretical model in an econometric model using a U.S. panel of foreign and domestic investments at the sector level over the period 1999-2005. The results of our panel with random and fixed sector effects confirm the findings by Desai et al. (2005b) for the estimated sign of foreign investment. Table 1 (columns 1 and 2) shows that the estimated coefficient is equal to 0.10 with random and with fixed effects. Column 3 shows

\footnotetext{
${ }^{17} \mathrm{~A}$ more complete description of the BEA data on the operations of U.S. multinational companies can be found in Slaughter (2000).
} 
that accounting for a common autoregressive term in the disturbances (estimated at a value of 0.6) decreases the estimated coefficient in the random effects model slightly to 0.09. ${ }^{18}$

The main novelty in the regressions is to allow for sector specific estimates of the coefficient for foreign investment. Table 2 splits the sample in manufacturing and non-manufacturing sectors and shows the regression results for both categories with random effects across sectors. The sign of the link between foreign investment and domestic investment is opposite for the manufacturing and the non-manufacturing sectors. While the sign is positive and significantly different from zero for the non-manufacturing sectors, the sign is negative for the manufacturing sectors. Hence, under the assumption that vertical MNEs are primarily active in manufacturing sectors and horizontal MNEs are primarily active in non-manufacturing sectors, we can confirm our first hypothesis that there is a positive relationship between domestic and foreign capital expenditures when MNEs are horizontal while foreign capital expenditures have a negative effect on domestic capital formation when MNEs are vertical. Assuming a normal distribution for the parameter estimate, there is a probability of around $7 \%$ that the coefficient for foreign investment is positive in the manufacturing sectors. In the non-manufacturing sectors, the confidence interval shows that the probability of a negative sign for foreign investment can be neglected.

As a further test for differences in the link between domestic and foreign investment, we include in table 2 interaction terms between foreign investment and centralized labor share in a sector and between foreign investment and the centralized share of the intermediate good produced by the U.S. parent. In line with the predictions from the theoretical model (hypothesis H3), for the manufacturing sectors the sign for the interaction term is positive for the share of the intermediate good while negative, though only weakly significant, for the interaction with the labor share.

The results indicate that manufacturing sectors with an average labor share in the foreign affiliate $\left(\phi_{2}\right)$ and an average share of intermediate good imports by the affiliate $(\alpha)$ are characterized by a negative relationship between foreign and domestic investment. If the labor share is relatively low and the share of the intermediate good is relatively high, however, there is a possibility that the sign for foreign investment becomes positive. Examples of such sectors are sectors with code 3342 (communications equipment) and with code 3361-3363 (motor vehicles, bodies and trailers, and parts); see Table A1.

\footnotetext{
${ }^{18}$ We also estimated a dynamic panel model based on system GMM (Arellano and Bover, 1995; Blundell and Bond, 1998), but, due to the limited number of sectors vis-a-vis the number of instruments, the estimates depended heavily on the model specification.
} 


\section{Conclusions}

Our paper has shown a clear difference between horizontal and vertical multinationals in explaining the link between domestic and foreign capital expenditures. In the analytical general equilibrium model we derive a complementary relationship between domestic and foreign capital expenditures if multinational activity is horizontal. However, if multinational activity is vertical, the relationship between domestic and foreign capital expenditures is substitutional or complementary, depending on the firms' technologies.

We test out theoretical implications with a panel of U.S. multinationals and find empirical support. First, we find that horizontal multinational activity leads to a complementary relationship between domestic and foreign capital expenditures, irrespective of the firms' technologies. Second, we find a substitutional relationship between domestic and foreign capital expenditures if multinational activity is vertical. In order to refine our empirical results, we show that the empirical influence of the firms' technology parameters on this substitutional link is as predicted by the theoretical model. 


\section{References}

Arndt, C., Buch, C.M., Schnitzer, M., 2007. FDI and Domestic Investment: An IndustryLevel View. CEPR Working Paper No. 6464.

Arrelano, M., Bover O., 1995. Another Look at the Instrumental Variables Estimation of Error-Components Models. Journal of Econometrics 68, 29-51.

Baxter, M., 1992. Fiscal Policy, Specialization, and Trade in the Two-Sector Model: the Return of Ricardo? Journal of Political Economy 100, 713-744.

Blomström, M., Kokko, A., 1997. How Foreign Investment Affects Host Countries. World Bank Policy Research Paper No. 1745.

Blundell, R., Bond, S., 1998. Initial Conditions and Moment Restrictions in Dynamic Panel Data Models. Journal of Econometrics 87, 115-143.

Braunerhjelm, P., Oxelheim, L., Thulin, P., 2005. The relationship between domestic and outward foreign direct investment: The role of industry-specific effects. International Business Review 14, 677-694.

Desai, M.A., Foley, C.F., Hines, J.R. Jr., 2005a. Foreign Direct Investment and the Domestic Capital Stock. American Economic Review 95, 33-38.

Desai, M.A., Foley, C.F., Hines, J.R. Jr., 2005b. Foreign Direct Investment and Domestic Economic Activity. Mimeo, Ross School of Business.

Dixit, A.K., Stiglitz, J.E., 1977. Monopolistic Competition and Optimum Product Diversity. American Economic Review 67, 297-308.

Feldstein, M.S., 1995. The Effects of Outbound Foreign Direct Investment on the Domestic Capital Stock. In: Feldman, M., Hines, J.R. Jr., Hubbard, and R.G., eds., The Effects of Taxation on Multinational Corporations. Chicago: University of Chicago Press, $43-66$.

Hanson, G.H., Mataloni, R.J. Jr., Slaughter, M.J., 2001. Expansion Strategies of U.S. Multinational Firms. In: Rodrik, D., Collings, S., eds., Brookings Trade Forum, 2001. Washington D.C.: Brookings Institution Press.

Herzer, D., Schrooten, M., 2008. Outward FDI and Domestic Investment in Two Industrialized Countries. Economics Letters 99, 139-143. 
Hummels, D., Rapoport, D., Yi, K.-M., 1998. Vertical Specialization and the Changing Nature of World Trade. FRBNY Economic Policy Review 4, 79-99.

Markusen, J.R., 2002. Multinational Firms and the Theory of International Trade. Cambridge, Mass.: The MIT Press.

Markusen, J.R., Venables, A.J., 2000. The Theory of Endowment, Intra-Industry and Multinational Trade. Journal of International Economics 52, 209-235.

Slaughter, M.J., 2000. Production Transfer within Multinational Enterprises and American Wages, Journal of International Economics 50, 449-472.

UNCTAD, 2007. World Investment Report. Geneva and New York: United Nations. 


\section{Appendix A - Comparative steady state analysis for the regime with hor- izontal multinational activity}

The system of equations (40)-(43) is differentiated totally.

Cramer's Rule is then used to calculate the ratio $\frac{d K_{H}}{d K_{F}}$. The expression $d K_{H}$ stands for the change of the domestic capital stock due to the exogenous shock and the expression $d K_{F}$ stands for the change of the foreign capital stock due to the exogenous shock.

If $\frac{d K_{H}}{d K_{F}}<0$, the domestic and the foreign capital stock are substitutes. If $\frac{d K_{H}}{d K_{F}}>0$, the domestic and the foreign capital stock are complements. In order to determine the sign of $\frac{d K_{H}}{d K_{F}}$, the following parameter restrictions are used in appendix A:

(i) $0.5<\alpha \leq 1, \quad$ (ii) $0 \leq \phi_{1}<0.5, \quad$ (iii) $\xi=\phi_{1} \cdot \alpha+\phi_{2} \cdot(1-\alpha)=\phi_{1} \cdot \alpha+\left(1-\phi_{1}\right) \cdot(1-\alpha)<0.5$. Note that restriction (iii) implies that good $X$ is capital intensive relative to good $Z$; restriction (iii) follows from restrictions $(i)$ and $(i i)$.

The steady state with horizontal multinational activity is now disturbed by four persistent exogenous shocks:

1 Symmetric demand shift $\left(d \gamma_{H}=d \gamma_{F}>0\right)$ :

$$
\frac{d K_{H}}{d K_{F}}=\frac{\left(L_{H}+\frac{r}{w} \cdot K_{H}+L_{F}+\frac{r}{w} \cdot K_{F}\right) \cdot 2 \cdot[2 \cdot \xi+\sigma \cdot(1-2 \cdot \xi)]}{\left(L_{H}+\frac{r}{w} \cdot K_{H}+L_{F}+\frac{r}{w} \cdot K_{F}\right) \cdot 2 \cdot[2 \cdot \xi+\sigma \cdot(1-2 \cdot \xi)]}=1 .
$$

The relationship between $K_{H}$ and $K_{F}$ is therefore complementary in the case of a symmetric demand shift.

$2 \quad$ Asymmetric demand shift $\left(d \gamma_{H}>0, d \gamma_{F}=0\right)$ :

$$
\frac{d K_{H}}{d K_{F}}=\frac{\left(L_{H}+\frac{r}{w} \cdot K_{H}\right) \cdot[2 \cdot \xi+\sigma \cdot(1-2 \cdot \xi)]}{\left(L_{H}+\frac{r}{w} \cdot K_{H}\right) \cdot[2 \cdot \xi+\sigma \cdot(1-2 \cdot \xi)]}=1
$$

Equation (54) shows that the relationship between $K_{H}$ and $K_{F}$ remains complementary, even if the demand shift is asymmetric.

3 Symmetric increase in population size $\left(d L_{H}=d L_{F}>0\right)$ :

$$
\frac{d K_{H}}{d K_{F}}=\frac{2 \cdot(\sigma \cdot(3-2 \cdot \xi)+2 \cdot \xi)}{2 \cdot(\sigma \cdot(3-2 \cdot \xi)+2 \cdot \xi)}=1 .
$$

The relationship between $K_{H}$ and $K_{F}$ is therefore complementary in the case of a symmetric increase in population size.

4 Asymmetric increase in population size $\left(d L_{H}>0\right.$ and $\left.d L_{F}=0\right)$ :

$$
\frac{d K_{H}}{d K_{F}}=\frac{2 \cdot \sigma}{2 \cdot \xi+\sigma \cdot(1-2 \cdot \xi)}>0, \quad \text { since } \xi \leq 0.5
$$

Equation (56) shows that the relationship between $K_{H}$ and $K_{F}$ remains complementary, even if the increase in population size is asymmetric. However, $K_{H}$ and $K_{F}$ are no perfect complements any more.

\section{Appendix B - Comparative steady state analysis for the regime with ver- tical multinational activity}

The system of equations (49)-(52) is differentiated totally.

Cramer's Rule is then used to calculate the ratio $\frac{d K_{H}}{d K_{F}}$. Again, the expression $d K_{H}$ stands for the change of the domestic capital stock due to the exogenous shock and the expression $d K_{F}$ stands for the change of the foreign capital stock due to the exogenous shock. 
If $\frac{d K_{H}}{d K_{F}}<0$, the domestic and the foreign capital stock are substitutes. If $\frac{d K_{H}}{d K_{F}}>0$, the domestic and the foreign capital stock are complements. In order to determine the sign of $\frac{d K_{H}}{d K_{F}}$, the following parameter restrictions are used in appendix B:

(i) $0.5<\alpha \leq 1, \quad$ (ii) $0 \leq \phi_{1}<0.5, \quad$ (iii) $\phi_{2}=1-\phi_{1}, \quad$ (iv) $\sigma>1, \quad$ (v) $\gamma_{H}=\gamma_{F}$ in the initial steady state, which is given by equations (49)-(52).

Restrictions ( $\mathrm{ii}$ ) and ( $\mathrm{iii}$ ) imply that intermediate good $v_{1}$ (intermediate good $v_{2}$ ) is capital (labor) intensive relative to good $Z$.

The steady state with vertical multinational activity is now disturbed by the same four persistent exogenous shocks as before:

$1 \quad$ Symmetric demand shift $\left(d \gamma_{H}=d \gamma_{F}>0\right):$

$$
\frac{d K_{H}}{d K_{F}}=\frac{\left(M_{H}+M_{F}\right) \cdot\left[1+\sigma-2 \cdot \alpha+4 \cdot \alpha \cdot \phi_{1} \cdot \sigma+2 \cdot \sigma^{2} \cdot \alpha \cdot\left(1-2 \cdot \phi_{1}\right)\right]}{\left(M_{H}+M_{F}\right) \cdot\left[4 \cdot \sigma \cdot \phi_{1} \cdot(1-\alpha) \cdot(\sigma-1)+(1-\alpha) \cdot 2 \cdot \sigma \cdot(2-\sigma)-1+\sigma+2 \cdot \alpha\right]},
$$

with $M_{H}=L_{H}+\frac{r}{w} \cdot K_{H}$ and $M_{F}=L_{F}+\frac{r}{w} \cdot K_{F}$. The numerator of $\frac{d K_{H}}{d K_{F}}$ is unambiguously positive since, first, $1+\sigma-2 \cdot \alpha>0$ and, second, $1-2 \cdot \phi_{1}>0$.

The denominator of $\frac{d K_{H}}{d K_{F}}$ is negative (positive) if $\phi_{1}$ is smaller (larger) than a threshold value $\Theta$, i.e. if the following holds:

$$
\phi_{1}<(>) \frac{1-\sigma-2 \cdot \alpha-(1-\alpha) \cdot 2 \cdot \sigma \cdot(2-\sigma)}{4 \cdot \sigma \cdot(1-\alpha) \cdot(\sigma-1)} \equiv \Theta .
$$

Therefore, $\frac{d K_{H}}{d K_{F}}>0$ if $\phi_{1}>\Theta$ and $\frac{d K_{H}}{d K_{F}}<0$ if $\phi_{1}<\Theta$.

For a given $\sigma$, the threshold value $\Theta$ is strictly positive (negative) if $\alpha$ is sufficiently small (large). ${ }^{19}$ Therefore, if $\alpha$ is sufficiently small, $\phi_{1}<\Theta$ is possible, i.e. $\frac{d K_{H}}{d K_{F}}<0$ is possible.

However, if $\alpha$ is such that $\Theta<0$, it always follows that $\phi_{1}>\Theta$. Therefore, if $\alpha$ is not sufficiently small, $\frac{d K_{H}}{d K_{F}}>0$ results.

Furthermore, the partial derivative $\frac{\partial \Theta}{\partial \alpha}$ is negative:

$$
\frac{\partial \Theta}{\partial \alpha}=\frac{-(\sigma+1)}{4 \cdot(\sigma-1)(\alpha-1)^{2} \cdot \sigma}<0
$$

Therefore, for given values of $\phi_{1}$ and $\sigma$, the inequality $\phi_{1}<\Theta$ is more likely to hold the smaller $\alpha$. The capital stocks $K_{H}$ and $K_{F}$ are accordingly more likely to be substitutes the smaller $\alpha$.

$$
\begin{aligned}
& 2 \text { Asymmetric demand shift }\left(d \gamma_{H}>0, d \gamma_{F}=0\right): \\
& \frac{d K_{H}}{d K_{F}}=\frac{\left(L_{H}+\frac{r}{w} \cdot K_{H}\right) \cdot\left[1+\sigma-2 \cdot \alpha+4 \cdot \alpha \cdot \phi_{1} \cdot \sigma+2 \cdot \sigma^{2} \cdot \alpha \cdot\left(1-2 \cdot \phi_{1}\right)\right]}{\left(L_{H}+\frac{r}{w} \cdot K_{H}\right) \cdot\left[4 \cdot \sigma \cdot \phi_{1} \cdot(1-\alpha) \cdot(\sigma-1)+(1-\alpha) \cdot 2 \cdot \sigma \cdot(2-\sigma)-1+\sigma+2 \cdot \alpha\right]}
\end{aligned}
$$

Equation (60) shows that the relationship between $K_{H}$ and $K_{F}$ is identical as in the case with a symmetric demand shift. Therefore, it still holds that the numerator of $\frac{d K_{H}}{d K_{F}}$ is unambiguously positive. Again, the denominator of $\frac{d K_{H}}{d K_{F}}$ is negative (positive) if $\phi_{1}$ is smaller (larger) than a threshold value $\Theta$, i.e. if the following holds:

$$
\phi_{1}<(>) \frac{1-\sigma-2 \cdot \alpha-(1-\alpha) \cdot 2 \cdot \sigma \cdot(2-\sigma)}{4 \cdot \sigma \cdot(1-\alpha) \cdot(\sigma-1)} \equiv \Theta .
$$

Again, for a given $\sigma$, the threshold value $\Theta$ is strictly positive if $\alpha$ is sufficiently small.

Therefore, it still holds that $K_{H}$ and $K_{F}$ are substitutes if $\phi_{1}$ and $\alpha$ are sufficiently small; $K_{H}$ and $K_{F}$ are complements otherwise.

\footnotetext{
${ }^{19}$ If $\alpha=0.5$ and $\sigma=5$, for example, the threshold value $\Theta$ equals 0.25 . If the factor share parameter $\phi_{1}$ is strictly smaller than $0.25, \frac{d K_{H}}{d K_{F}}<0$ results. However, if $\alpha=0.9$ and $\sigma=5$, for example, the threshold value $\Theta$ equals -0.35 . Even if $\phi_{1}=0, \frac{d K_{H}}{d K_{F}}>0$ results.
} 
3 Symmetric increase in population size $\left(d L_{H}=d L_{F}>0\right)$ :

$$
\frac{d K_{H}}{d K_{F}}=\frac{\Delta_{1}+\Delta_{2}+\Delta_{3}+\Delta_{4}}{\Delta_{5}+\Delta_{6}+\Delta_{7}+\Delta_{8}}
$$

with

$\Delta_{1}=2 \cdot \gamma \cdot(\alpha \cdot(\sigma-2)+1)>0 \quad$ since $0.5<\alpha \leq 1$ and $\sigma>1$,

$\Delta_{2}=\sigma \cdot(1-\gamma)+2 \cdot \phi_{1} \cdot \gamma \cdot \sigma \cdot(1+2 \cdot \alpha)>0 \quad$ since $0 \leq \gamma \leq 1$,

$\Delta_{3}=\gamma \cdot \sigma^{2} \cdot\left(1-2 \cdot \phi_{1}\right)>0 \quad$ since $0 \leq \phi_{1}<0.5$,

$\Delta_{4}=\sigma^{2} \cdot\left(2 \cdot \alpha \cdot \gamma \cdot\left(1-2 \cdot \phi_{1}\right)+1\right)>0 \quad$ since $0 \leq \phi_{1}<0.5$,

$\Delta_{5}=2 \cdot \gamma \cdot(2 \cdot \alpha-1)+6 \cdot \gamma \cdot \sigma \cdot(1-\alpha)>0 \quad$ since $0.5<\alpha \leq 1$,

$\Delta_{6}=\sigma \cdot\left(\gamma \cdot\left(\phi_{1} \cdot(4 \cdot \alpha-6)+1\right)+1\right)>0 \quad$ since $0.5<\alpha \leq 1, \quad 0 \leq \phi_{1}<0.5, \quad \sigma>1$ and $0 \leq \gamma \leq 1$,

$\Delta_{7}=\sigma^{2} \cdot(\gamma \cdot(2 \cdot \alpha-3)+1) \lesseqgtr 0 \quad$ since $0.5<\alpha \leq 1$ and $0 \leq \gamma \leq 1$,

$\Delta_{8}=\gamma \cdot \phi_{1} \cdot \sigma^{2} \cdot(6-4 \cdot \alpha)>0 \quad$ since $0.5<\alpha \leq 1$.

The numerator of $\frac{d K_{H}}{d K_{F}}$ is positive since $\Delta_{1}, \Delta_{2}, \Delta_{3}$ and $\Delta_{4}$ are strictly larger than zero.

However, the sign of the denominator is ambiguous. $\Delta_{5}, \Delta_{6}$ and $\Delta_{8}$ are strictly larger than zero. $\Delta_{7}$, in contrast, may be negative.

It can be shown that the sum $\Delta_{5}+\Delta_{6}+\Delta_{7}+\Delta_{8}$ is negative (positive) if $\phi_{1}$ is smaller (larger) than a threshold value $\Upsilon$, i.e. if the following holds:

$$
\phi_{1}<(>) \frac{-2 \cdot \gamma \cdot(2 \cdot \alpha-1)-6 \cdot \gamma \cdot \sigma \cdot(1-\alpha)-\gamma \cdot \sigma-\sigma-\sigma^{2} \cdot \gamma \cdot(2 \cdot \alpha-3)-\sigma^{2}}{(6-4 \cdot \alpha) \cdot \gamma \cdot \sigma \cdot(\sigma-1)} \equiv \Upsilon .
$$

Therefore, $\frac{d K_{H}}{d K_{F}}<0$ if $\phi_{1}<\Upsilon$ and $\frac{d K_{H}}{d K_{F}}>0$ if $\phi_{1}>\Upsilon$.

For given values of $\sigma$ and $\gamma$, the threshold value $\Upsilon$ is strictly positive (negative) if $\alpha$ is sufficiently small (large). ${ }^{20}$

Therefore, if $\alpha$ is sufficiently small, $\phi_{1}<\Upsilon$ is possible, i.e. $\frac{K_{H}}{K_{F}}<0$ is possible.

However, if $\alpha$ is such that $\Upsilon<0$, it always follows that $\phi_{1}>\Upsilon$, i.e. $K_{H}$ and $K_{F}$ are complements if $\alpha$ is not sufficiently small.

Furthermore, it can be shown that the partial derivative $\frac{\partial \Upsilon}{\partial \alpha}$ is negative:

$$
\frac{\partial \Upsilon}{\partial \alpha}=\frac{4 \cdot \gamma+\sigma \cdot(1+\sigma-2 \cdot \gamma)}{(1-\sigma) \cdot(2 \cdot \alpha-3)^{2} \cdot \gamma \cdot \sigma}<0 .
$$

Therefore, for given values of $\phi_{1}, \sigma$ and $\gamma$, the inequality $\phi_{1}<\Upsilon$ is more likely to hold the smaller $\alpha$. The capital stocks $K_{H}$ and $K_{F}$ are accordingly more likely to be substitutes the smaller $\alpha$.

$$
\begin{aligned}
& 4 \text { Asymmetric increase in country size }\left(d L_{H}>0 \text { and } d L_{F}=0\right) \text { : } \\
& \frac{d K_{H}}{d K_{F}}=\frac{2 \cdot \alpha \cdot \gamma \cdot(\sigma-1)+\gamma \cdot \sigma^{2} \cdot\left(1-2 \cdot \phi_{1}\right)+\sigma \cdot(1+\sigma-2 \cdot \gamma)+\gamma+2 \cdot \phi_{1} \cdot \gamma \cdot \sigma}{4 \cdot \sigma \cdot \phi_{1} \cdot(1-\alpha) \cdot(\sigma-1)+(1-\alpha) \cdot 2 \cdot \sigma \cdot(2-\sigma)-1+\sigma+2 \cdot \alpha} .
\end{aligned}
$$

The numerator of $\frac{d K_{H}}{d K_{F}}$ is unambiguously positive since, first, $1-2 \cdot \phi_{1}>0$ and, second, $1+\sigma-2 \cdot \gamma>0$.

The denominator of $\frac{d K_{H}}{d K_{F}}$ is negative (positive) if $\phi_{1}$ is smaller (larger) than a threshold value $\Xi$, i.e., if the following holds:

$$
\phi_{1}<(>) \frac{1-\sigma-2 \cdot \alpha-(1-\alpha) \cdot 2 \cdot \sigma \cdot(2-\sigma)}{4 \cdot \sigma \cdot(1-\alpha) \cdot(\sigma-1)} \equiv \Xi .
$$

Therefore, $\frac{d K_{H}}{d K_{F}}<0$ if $\phi_{1}<\Xi$ and $\frac{d K_{H}}{d K_{F}}>0$ if $\phi_{1}>\Xi$.

Since th threshold value $\Xi$ equals the threshold value $\Theta($ cf. equation (58)), it follows again that $\Xi$ increases with a decreasing $\alpha$. Therefore, $\phi_{1}<\Xi$ is more likely to hold the smaller $\alpha$. The capital stocks $K_{H}$ and $K_{F}$ are accordingly more likely to be substitutes the smaller $\alpha$.

However, if $\alpha$ is such that $\Xi<0$, it always follows that $\phi_{1}>\Xi$, i.e. $K_{H}$ and $K_{F}$ are complements if $\alpha$ is not sufficiently small.

\footnotetext{
${ }^{20}$ If, for example, $\alpha=0.5, \sigma=10$ and $\gamma=0.8$, the threshold value $\Upsilon$ equals 0.0625 . If the factor share parameter $\phi_{1}$ is strictly smaller than $0.0625, \frac{d K_{H}}{d K_{F}}<0$ results. However, if, for example, $\alpha=0.75, \sigma=10$ and $\gamma=0.8$, the threshold value $\Upsilon$ equals -0.05 . Even if $\phi_{1}, \frac{d K_{H}}{d K_{F}}>0$ results in this case.
} 
Figure 1: allocation of production activities across countries

chart 1: horizontal multinational firms with headquarters in country $i, j=H, F, i \neq j$ : country $i$ :

country $j$ :

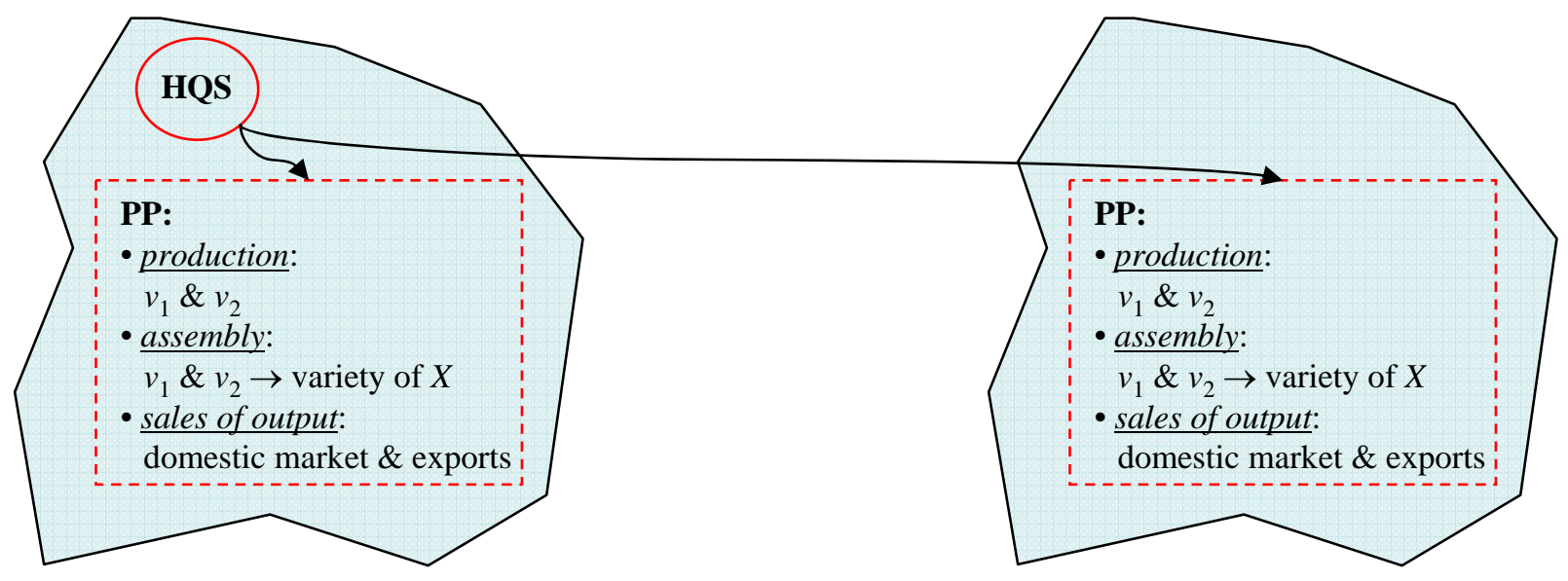

chart 2: vertical multinational firms with headquarters in country $H$ : country $H$ : country $F$ :

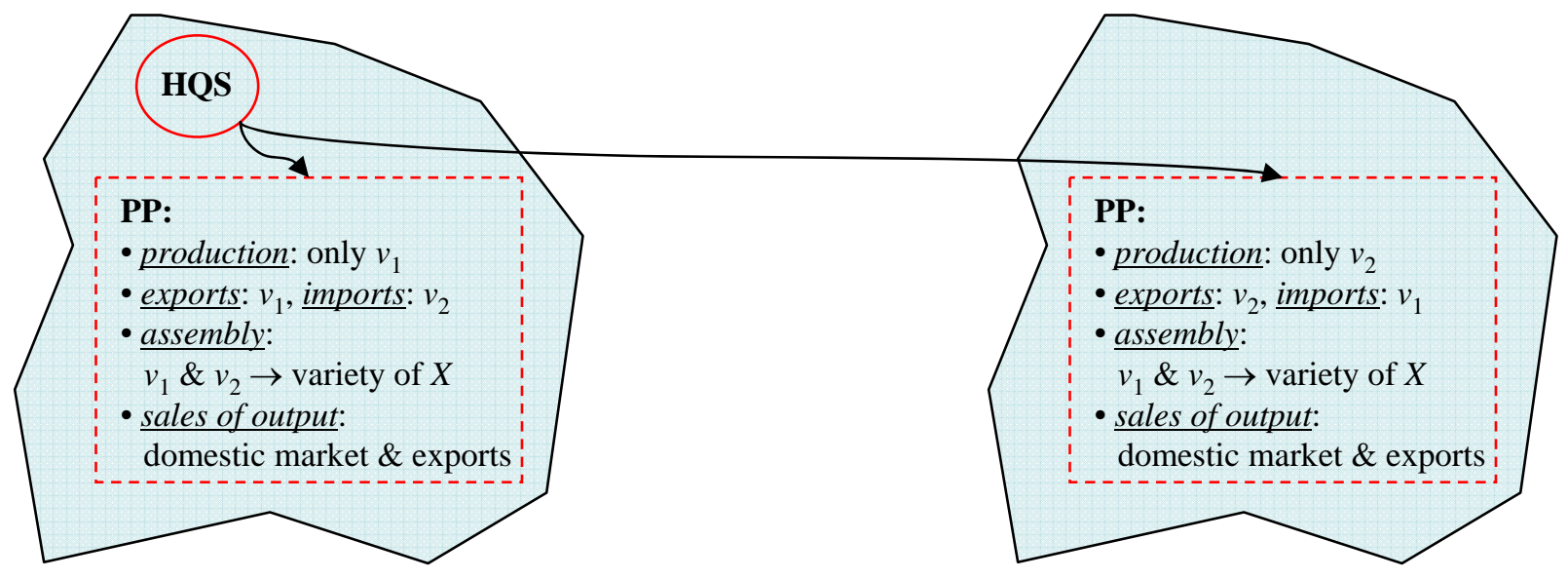

chart 3: vertical multinational firms with headquarters in country $F$ : country $H$ : country $F$ :

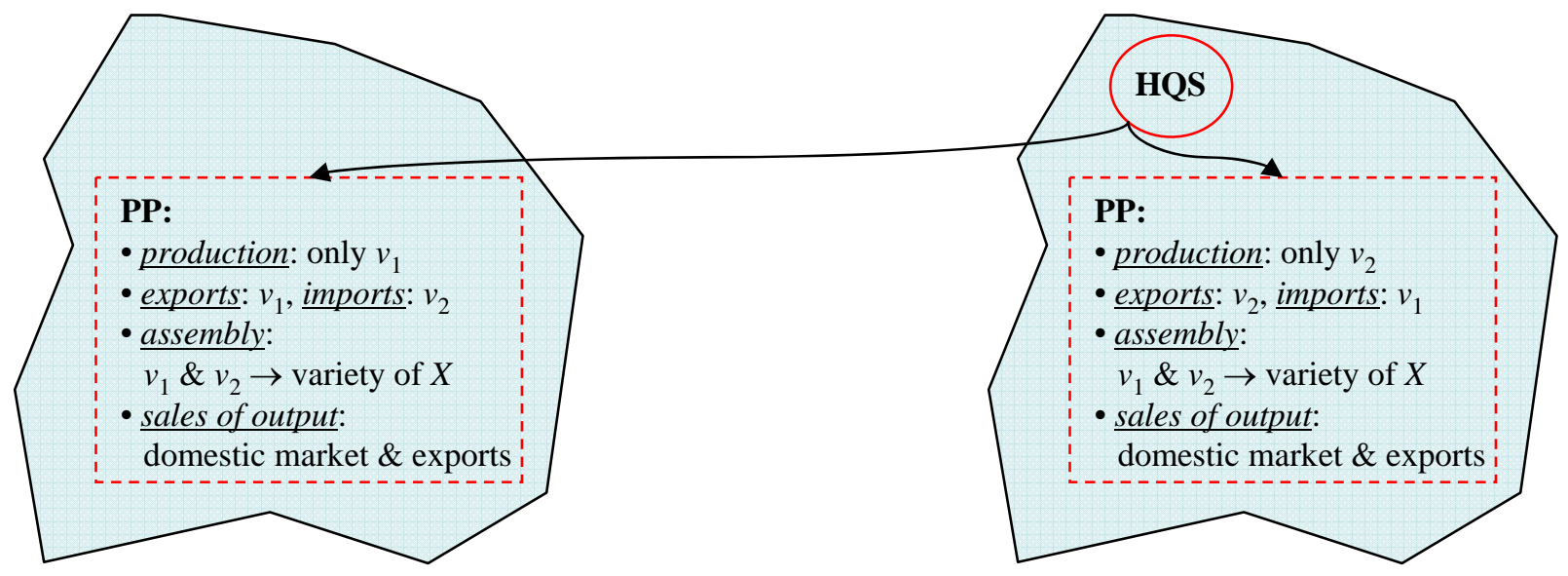

Note: HQS $\equiv$ headquarter services; $\mathrm{PP} \equiv$ production plant 
Figure 2: summary of comparative steady state results

\section{Horizontal multinationals}

type of shock firms` technologies

relationship between capital stocks $K_{H}$ and $K_{F}$

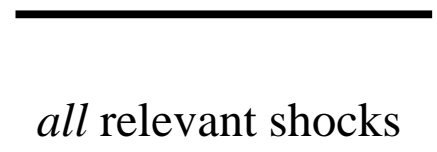

\begin{tabular}{c}
\hline all relevant technology \\
parameters
\end{tabular}

\section{Vertical multinationals}

type of shock firms` technologies

all relevant shocks
- intermediate goods have sufficiently different factor shares

- final good uses labor intensive intermediate good sufficiently intensively all other relevant technology parameters relationship between capital stocks $K_{H}$ and $K_{F}$ 
TABLES

Table 1: Basic regression results

\begin{tabular}{|l|c|c|c|}
\hline Independent Variable & Random effects & Fixed effects & $\begin{array}{c}\text { Random effects } \\
\text { Common AR(1) term } \\
\text { in errors. }\end{array}$ \\
\hline Constant & $0.165^{* * *}$ & & $0.166^{* * *}$ \\
& $(0.014)$ & $0.197^{* * *}$ & $(0.011)$ \\
\hline Foreign Investment & $0.104^{* * *}$ & $0.090^{* * *}$ & $0.089^{* * *}$ \\
& $(0.014)$ & $(0.002)$ & $(0.010)$ \\
\hline Year_2000 & -0.013 & $-0.014^{*}$ & -0.013 \\
& $(0.017)$ & $(0.008)$ & $(0.014)$ \\
\hline Year_2001 & 0.010 & 0.009 & 0.010 \\
& $(0.017)$ & $(0.014)$ & $(0.017)$ \\
\hline Year_2002 & $-0.028^{*}$ & -0.029 & $-0.028^{*}$ \\
& $(0.017)$ & $(0.019)$ & $(0.019)$ \\
\hline Year_2003 & $-0.039^{* *}$ & $-0.040^{* *}$ & $\left(0.039^{* *}\right.$ \\
& $(0.017)$ & $(0.018)$ & $-0.071^{* * *}$ \\
\hline Year_2004 & $-0.071^{* * *}$ & $-0.072^{* * *}$ & $(0.020)$ \\
\hline Year_2005 & $(0.014)$ & $(0.018)$ & $-0.064^{* * *}$ \\
& $-0.064^{* * *}$ & $-0.066^{* * *}$ & $(0.020)$ \\
\hline \# obs. & $(0.014)$ & $(0.013)$ & 294 \\
\hline
\end{tabular}

Notes: The dependent variable is total domestic capital expenditures of U.S. multinational firms in a sector divided by total value added of the multinational firms in the sector. Foreign investment is defined as foreign capital expenditures of U.S. multinational firms in a sector divided by total value added of the multinational firms in the sector. Standard errors that correct for clustering appear in parentheses. $* * *, * *$ and $*$ denote significance at the $1 \%, 5 \%$ and $10 \%$ level, respectively. 
Table 2: Regression results for non-manufacturing and manufacturing sectors with interaction effects.

\begin{tabular}{|l|c|c|c|c|}
\hline & \multicolumn{2}{|c|}{ Non-Manufacturing } & \multicolumn{2}{c|}{ Manufacturing } \\
\hline Constant & $0.183^{* * *}$ & $0.166^{* * *}$ & $0.157^{* * *}$ & $(0.013)$ \\
& $(0.025)$ & $(0.019)$ & -0.140 & $(0.013)$ \\
\hline Foreign Investment & $0.104^{* * *}$ & 0.112 & $(0.096)$ & $-0.214^{* *}$ \\
& $(0.013)$ & $(0.176)$ & & $(0.108)$ \\
\hline Foreign Investment $*$ & & -0.192 & $\left(0.892^{*}\right.$ \\
Centralized Labor & & $(0.268)$ & & $(0.502)$ \\
Share $\left(\varphi_{2}-\bar{\varphi}_{2}\right)$ & & & & $0.291^{* *}$ \\
\hline Foreign Investment $*$ & & 0.380 & & $(0.131)$ \\
Centralized Share & & $(0.556)$ & & 136 \\
Intermediate $(\alpha-\bar{\alpha})$ & & 140 & 140 & \\
\hline \# obs. & 154 & & & \\
\hline
\end{tabular}

Notes: The dependent variable is total domestic capital expenditures of U.S. multinational firms in a sector divided by total value added of the multinational firms in the sector. Foreign investment is defined as foreign capital expenditures of U.S. multinational firms in a sector divided by total value added of the multinational firms in the sector. Standard errors that correct for clustering appear in parentheses. $* * *, * *$ and $*$ denote significance at the $1 \%, 5 \%$ and $10 \%$ level, respectively. Sectors with NAICS codes 5231 and 5232-5239 are dropped due to missing observations for labor share. 
Table A1: Industries in the panel

\begin{tabular}{|c|c|c|c|c|c|}
\hline $\begin{array}{l}\text { NAICS } \\
2002 \\
\text { code }\end{array}$ & Industry & $\begin{array}{l}\text { Manufacturing } \\
\text { (1=Yes) }\end{array}$ & $\begin{array}{l}\text { Average wage } \\
\text { in affiliates }\end{array}$ & $\begin{array}{l}\text { Affiliate wages I } \\
\text { Domestic wages }\end{array}$ & $\begin{array}{l}\text { Exports to affiliates I } \\
\text { Value added of } \\
\text { affiliates }\end{array}$ \\
\hline 11 & Agriculture, forestry, fishing, and hunting & 0 & $\$ 8,500$ & 0.31 & 0.233 \\
\hline 211 & Oil and Gas Extraction & 0 & $\$ 49,000$ & 0.47 & 0.008 \\
\hline 212 & Other mining & 0 & $\$ 32,800$ & 0.45 & 0.094 \\
\hline 23 & Construction & 0 & $\$ 37,800$ & 0.63 & 0.462 \\
\hline 311 & Food & 1 & $\$ 26,500$ & 0.61 & 0.134 \\
\hline 324 & Petroleum and coal products & 1 & $\$ 62,300$ & 0.77 & 0.019 \\
\hline 3251 & Basic chemicals & 1 & $\$ 43,900$ & 0.58 & 0.318 \\
\hline 3252 & Resins and synthetic rubber, fibers, and filaments & 1 & $\$ 52,300$ & 0.66 & 0.552 \\
\hline 3254 & Pharmaceuticals and medicines & 1 & $\$ 45,700$ & 0.50 & 0.136 \\
\hline 3256 & $\begin{array}{l}\text { Soap, cleaning compounds, and toilet } \\
\text { preparations }\end{array}$ & 1 & $\$ 28,700$ & 0.45 & 0.145 \\
\hline 3259 & Other Chemicals & 1 & $\$ 46,800$ & 0.68 & 0.594 \\
\hline 331 & Primary metals & 1 & $\$ 31,200$ & 0.53 & 0.140 \\
\hline 332 & Fabricated metal products & 1 & $\$ 29,900$ & 0.62 & 0.278 \\
\hline 3331 & Agriculture, construction, and mining machinery & 1 & $\$ 37,200$ & 0.52 & 0.537 \\
\hline 3332 & Industrial machinery & 1 & $\$ 45,100$ & 0.75 & 0.388 \\
\hline 3339 & Other machinery & 1 & $\$ 35,200$ & 0.67 & 0.328 \\
\hline 3341 & Computers and peripheral equipment & 1 & $\$ 26,700$ & 0.35 & 0.416 \\
\hline 3342 & Communications equipment & 1 & $\$ 32,400$ & 0.40 & 0.781 \\
\hline 3343 & Audio and video equipment & 1 & $\$ 14,400$ & 0.21 & NA \\
\hline 3344 & Semiconductors and other electronic components & 1 & $\$ 20,000$ & 0.29 & 0.621 \\
\hline 3345 & Navigational, measuring, and other instruments & 1 & $\$ 43,800$ & 0.65 & 0.462 \\
\hline 335 & Electrical equipment, appliances, and components & 1 & $\$ 19,800$ & 0.43 & 0.302 \\
\hline $\begin{array}{l}3361- \\
3363\end{array}$ & Motor vehicles, bodies and trailers, and parts & 1 & $\$ 34,900$ & 0.53 & 1.113 \\
\hline $\begin{array}{l}3364- \\
3369\end{array}$ & Other Transportation equipment & 1 & $\$ 26,500$ & 0.56 & 0.602 \\
\hline 42 & Wholesale trade & 0 & $\$ 50,700$ & 0.87 & 0.470 \\
\hline $44-45$ & Retail trade & 0 & $\$ 15,100$ & 0.70 & 0.186 \\
\hline
\end{tabular}




\begin{tabular}{|c|c|c|c|c|c|}
\hline $48-49$ & Transportation and warehousing & 0 & $\$ 30,400$ & 0.53 & 0.025 \\
\hline 51 & Information & 0 & $\$ 39,100$ & 0.67 & 0.000 \\
\hline 5231 & $\begin{array}{l}\text { Securities, commodity contracts, and other } \\
\text { intermediation and related activities }\end{array}$ & 0 & $\$ 180,400$ & 1.22 & 0.001 \\
\hline $\begin{array}{l}5232- \\
5239\end{array}$ & Other finance, except depository institutions & 0 & $\$ 45,200$ & 0.57 & 0.000 \\
\hline 524 & Insurance carriers and related activities & 0 & $\$ 48,700$ & 0.71 & 0.000 \\
\hline 531 & Real estate & 0 & $\$ 31,600$ & 0.51 & 0.000 \\
\hline 532 & Rental and leasing (except real estate) & 0 & $\$ 38,100$ & 0.96 & 0.011 \\
\hline 5413 & Architectural, engineering, and related services & 0 & $\$ 53,400$ & 0.82 & 0.000 \\
\hline 5415 & Computer systems design and related services & 0 & $\$ 64,500$ & 0.77 & 0.077 \\
\hline 5416 & Management, scientific, and technical consulting & 0 & $\$ 94,100$ & 1.02 & 0.000 \\
\hline 5419 & $\begin{array}{l}\text { Other Professional, Technical and Scientific } \\
\text { Services }\end{array}$ & 0 & $\$ 33,300$ & 0.59 & 0.009 \\
\hline 56 & Administration, support, and waste management & 0 & $\$ 22,600$ & 0.87 & 0.004 \\
\hline 62 & Health care and social assistance & 0 & $\$ 25,400$ & 0.62 & 0.035 \\
\hline 721 & Accommodation & 0 & $\$ 21,100$ & 0.99 & 0.000 \\
\hline 722 & Food services and drinking places & 0 & $\$ 11,100$ & 0.63 & 0.011 \\
\hline 81 & Miscellaneous services & 0 & $\$ 24,200$ & 1.06 & 0.099 \\
\hline
\end{tabular}

Note: Numbers relate to the median over the years 1999-2005. Average wage in affiliates is calculated as the total compensation of employees in the affiliates divided by the total employment in the affiliates. Affiliate wages / Domestic wages is calculated as the average wage in affiliates divided by the average wage at the parent firm in the U.S. Exports to affiliates / Value added of affiliates is calculated as the value of U.S. exports shipped from U.S. parents to foreign affiliates divided by the value added of the foreign affiliates. Correlation between Manufacturing and Average wage in affiliates is -0.15 . Correlation between Manufacturing and Affiliate wages / domestic wages is 0.44. Correlation between Manufacturing and Exports to affiliates / Value added is 0.64 
Table A2: descriptive statistics of variables

\begin{tabular}{|l|l|l|l|l|l|l|l|}
\hline & \multicolumn{2}{|l|}{$\begin{array}{l}\text { Whole Sample } \\
(\mathrm{N}=294)\end{array}$} & \multicolumn{2}{l|}{$\begin{array}{l}\text { Manufacturing } \\
(\mathrm{N}=140)\end{array}$} & \multicolumn{2}{l|}{$\begin{array}{l}\text { Non- } \\
\text { manufacturing } \\
\text { (N=154) }\end{array}$} \\
\hline Variable & Description & Mean & $\begin{array}{l}\text { Standard } \\
\text { Deviation }\end{array}$ & Mean & $\begin{array}{l}\text { Standard } \\
\text { Deviation }\end{array}$ & Mean & $\begin{array}{l}\text { Standard } \\
\text { Deviation }\end{array}$ \\
\hline $\begin{array}{l}\text { Domestic } \\
\text { Investment }\end{array}$ & $\begin{array}{l}\text { Domestic capital } \\
\text { expenditures / Value } \\
\text { added of US parent } \\
\text { companies }\end{array}$ & 0.18 & 0.14 & 0.15 & 0.07 & 0.20 & 0.18 \\
\hline $\begin{array}{l}\text { Foreign } \\
\text { Investment }\end{array}$ & $\begin{array}{l}\text { Foreign capital } \\
\text { expenditures / Value } \\
\text { added of US parent } \\
\text { companies }\end{array}$ & 0.10 & 0.43 & 0.05 & 0.06 & 0.15 & 0.58 \\
\hline $\begin{array}{l}\text { Share } \\
\text { Intermediate }\end{array}$ & $\begin{array}{l}\text { Exports shipped by } \\
\text { U.S. parents to foreign } \\
\text { affiliates / Value } \\
\text { added of foreign } \\
\text { affiliates }\end{array}$ & 0.26 & 0.29 & 0.43 & 0.29 & 0.09 & 0.15 \\
\hline $\begin{array}{l}\text { Compensation of } \\
\text { employees of foreign } \\
\text { affiliates / Value } \\
\text { added of foreign } \\
\text { affiliates }\end{array}$ & 0.53 & 0.20 & 0.50 & 0.15 & 0.56 & 0.23 \\
\hline
\end{tabular}

